\title{
Malolactic Fermentation: The ABC's of MLF
}

\author{
E. Lerm ${ }^{2}$, L. Engelbrecht ${ }^{2}$ and M. du Toit ${ }^{1,2 *}$
}

(1) Department of Viticulture and Oenology, Stellenbosch University, Private Bag X1, Matieland (Stellenbosch), South Africa

(2) Institute for Wine Biotechnology, Stellenbosch University, Private Bag X1, Matieland (Stellenbosch), South Africa

Submitted for publication: July 2010

Accepted for publication: September 2010

Key words: Malolactic fermentation, lactic acid bacteria, inoculation, aroma

\begin{abstract}
There are two main fermentations associated with the winemaking process. Alcoholic fermentation is conducted by the yeast culture and malolactic fermentation takes place as a result of the metabolic activity of lactic acid bacteria, specifically from the genera Oenococcus, Lactobacillus, Pediococcus and Leuconostoc. Malolactic fermentation is defined as the conversion of malic acid to lactic acid and $\mathrm{CO}_{2}$ and besides deacidification also contributes to microbial stability and modification of the aroma profile. This paper aims to provide a comprehensive review discussing all the main aspects and factors related to malolactic fermentation, including practical considerations for monitoring and ensuring a successful fermentation.
\end{abstract}

\section{INTRODUCTION}

Malolactic fermentation (MLF) is an intricate process that usually follows after the completion of alcoholic fermentation (AF) by yeasts. Although MLF is regarded as a secondary fermentation process, it plays an integral role in the production of the majority of red wines, as well as some white cultivars including Chardonnay and some sparkling wines. There are three main reasons for conducting MLF in wine. Firstly, the deacidification of the wine with a concomitant increase in $\mathrm{pH}$, secondly, to contribute to the microbial stability by the removal of malic acid as a possible carbon substrate and thirdly, the modification of the wine aroma profile (Davis et al., 1988; Kunkee, 1991; Maicas et al., 1999; Liu, 2002; Ugliano et al., 2003). In cooler climate countries the deacidification process is regarded as the most important modification associated with MLF, while the change in the sensory profile of the wine is a more important consideration in countries where deacidification is of less significance, i.e. warmer regions where lower concentrations of malic acid are present in the grapes.

The MLF reaction is defined as the conversion of L-malic acid, a dicarboxylic acid, to L-lactic acid, a monocarboxylic acid, with the production of $\mathrm{CO}_{2}$. The reaction is catalysed by lactic acid bacteria (LAB), including bacteria from the genera Oenococcus, Lactobacillus, Pediococcus and Leuconostoc (Wibowo et al., 1985). Of these, Oenococcus oeni is best adapted to the harsh wine environment, including conditions of high alcohol, low $\mathrm{pH}$ and the presence of sulphur dioxide $\left(\mathrm{SO}_{2}\right)$ (Wibowo et al., 1985; Davis et al., 1988; Drici-Cachon et al., 1996; LonvaudFunel, 1999). Various review articles on MLF have appeared over the years (Wibowo et al., 1985; Davis et al., 1988; Kunkee, 1991), with increasing amounts of information being generated regarding this important step in the winemaking process as well as the characterisation of the microorganisms involved. Some of the most recent review articles include Lonvaud-Funel (1999), Liu (2002) and Bauer \& Dicks (2004), with the focus falling on the metabolism of wine associated LAB, specifically $O$. oeni, and factors influencing LAB and MLF. In addition to the information being generated on the metabolic processes associated with wine $\mathrm{LAB}$, the molecular aspects of LAB are also being investigated. At the beginning of the $21^{\text {st }}$ century, the DOE Joint Genome Institute commenced the sequencing of the entire genome of $O$. oeni PSU-1, a strain isolated by Beelman and co-workers (Bartowsky, 2005). The genome is now fully sequenced, which allows for more intensive studies regarding the physiology, genetic diversity and performance of $O$. oen $i$ starter cultures.

The focus of this literature review will be to summarise key aspects associated with the process of MLF. The MLF reaction as well as the main LAB found in wine will be discussed. The use of commercial starter cultures and the influence of different inoculation times are considered. Various factors influence this fermentation process, such as wine parameters, microorganisms and compounds originating from the grapes, and will also be discussed. As recent research focus has fallen on the organoleptic changes in wine undergoing MLF, the important aroma compounds responsible for MLF aroma characteristics are critically reviewed. The final section of the review will highlight some practical considerations for the monitoring of MLF to ensure the successful completion of MLF with a positive contribution to the aroma profile.

\section{MALOLACTIC FERMENTATION}

Lactic acid bacteria possess three possible enzymatic pathways for the conversion of L-malic acid to L-lactic acid and $\mathrm{CO}_{2}$. The first is the direct conversion of malic acid to lactic acid via malate decarboxylase, also known as the malolactic enzyme (MLE). This reaction requires $\mathrm{NAD}^{+}$and $\mathrm{Mn}^{2+}$ as cofactors and no free intermediates are produced during this decarboxylation reaction. The rate of malate decarboxylation by LAB is correlated to the specific malolactic activity of the bacterial cell (Bartowsky, 2005). The main wine LAB utilise this pathway to generate lactic acid. A paper written by Lonvaud-Funel (1995) highlighted the main features of the malate decarboxylase $(m l e A)$ gene. The enzyme has been purified from various LAB species that were isolated from wines and grapes, including species from Lactobacillus and 
Leuconostoc (Lonvaud-Funel, 1995). The second pathway utilises the malic enzyme to convert L-malic acid to pyruvic acid, which is subsequently reduced by L-lactate dehydrogenase to lactic acid. The third possible pathway is the reduction of malate by malate dehydrogenase to oxaloacetate, followed by decarboxylation to pyruvate and reduction to lactic acid (Lonvaud-Funel, 1999).

The major physiological function of the malate fermentation pathway is to generate a proton motive force (PMF) as a means to acquire energy to drive essential cellular processes (Konings, 2002). The MLF reaction catalysed by the MLE enzyme can be divided into three stages: the uptake of L-malic acid by wine $\mathrm{LAB}$, the decarboxylation of L-malic acid to L-lactic acid and $\mathrm{CO}_{2}$ and the excretion of L-lactic acid together with a proton. The decarboxylation reaction yields an electrical potential $(\Delta \psi)$. The proton that is secreted during the decarboxylation reaction results in an increase in the internal $\mathrm{pH}$ of the bacterial cell which yields a pH gradient $\left(\Delta_{\mathrm{pH}}\right)$ across the membrane. These two components make up the PMF which then generate ATP via membrane ATPases. The PMF is sufficient to drive energy-consuming reactions e.g. the transport of metabolites (Henick-Kling, 1993; Versari et al., 1999).

\section{LACTIC ACID BACTERIA ASSOCIATED WITH WINE}

Lactic acid bacteria are coccoid to elongated cocci or rod-shaped bacilli, Gram-positive, non-sporing and non-respiring bacteria. As the name suggests, lactic acid is the major product formed during the fermentation of carbohydrates. Lactic acid bacteria species from the genera Leuconostoc, Pediococcus, Lactobacillus as well as $O$. oeni, are accountable for the changes to the wine matrix during the fermentation process (Wibowo et al., 1985). Oenococcus oeni has best adapted to the wine environment and concomitantly the majority of LAB present in wine belong to this species. Oenococcus oeni strains are also the selected bacteria used for commercial starter cultures (Wibowo et al., 1985; Davis et al., 1988; Drici-Cachon et al., 1996; Lonvaud-Funel, 1999).

\section{Evolution of the lactic acid bacteria population}

The evolution of LAB from the vineyard to the final vinification stages have been documented, but show considerable variability due to region, cultivar and vinification procedures. It is clear that there is a successional growth of several species of LAB during vinification (Wibowo et al., 1985; Boulton et al., 1996; Fugelsang \& Edwards, 1997). Oenococcus oeni is the main LAB species associated with wine; Pediococcus damnosus, Pediococcus parvulus and Pediococcus pentosaceus mostly occur after MLF and in higher $\mathrm{pH}$ wines and several Lactobacillus species also occur after MLF (Wibowo et al., 1985; Powell et al., 2006).

In the vineyard, the diversity and population density of LAB are very limited, especially in comparison to the indigenous yeast population found on grapes (Fugelsang \& Edwards, 1997). Organisms occur on grapes and leaf surfaces (Wibowo et al., $1985)$ but population numbers on undamaged grapes and grape must are rarely higher than $10^{3} \mathrm{CFU} / \mathrm{g}$ (Lafon-Lafourcade et al., 1983). The population size on grape surfaces depend in large on the maturity and sanitary state of the grapes (Wibowo et al., 1985; Jackson, 2008) and Pediococcus and Leuconostoc species occur on grapes more frequently than O. oeni (Jackson, 2008). Besides grape surfaces, bacterial strains can also be isolated from the cellar environment, including barrels and poorly sanitised winery equipment like pipes and valves (Donnelly, 1977; Boulton et al., 1996; Jackson, 2008).

Shortly after crushing and the start of AF, the LAB population in the grape must generally range from $10^{3}$ to $10^{4} \mathrm{CFU} / \mathrm{mL}$. The major species of LAB present at this stage include Lactobacillus plantarum, Lactobacillus casei, Leuconostoc mesenteroides, and P. damnosus, as well as $O$. oeni to a lesser extent (Wibowo et al., 1985; Lonvaud-Funel et al., 1991; Boulton et al., 1996; Powell et al., 2006). Most of these LAB species generally do not multiply and decline towards the end of AF, with the exception of O. oeni (Wibowo et al., 1985; Lonvaud-Funel et al., 1991; Van Vuuren \& Dicks, 1993; Fugelsang \& Edwards, 1997; Volschenk et al., 2006). The decrease could be attributed to increased ethanol concentrations, high $\mathrm{SO}_{2}$ concentrations, low $\mathrm{pH}$, low temperatures, the nutritional status and competitive interactions with the yeast culture (Fugelsang \& Edwards, 1997; Volschenk et al., 2006).

After the completion of AF and the bacterial lag phase, the surviving bacterial cells, most commonly $O$. oeni, start to multiply. This phase is characterised by vigorous bacterial growth and the start of MLF is induced when bacterial populations reach $10^{6} \mathrm{CFU} / \mathrm{mL}$ (Wibowo et al., 1985; Lonvaud-Funel, 1999). The $\mathrm{pH}$ of the wine is imperative in determining which species of LAB are present, with values above $\mathrm{pH} 3.5$ favouring the growth of Lactobacillus and Pediococcus species, whereas the O. oeni population tend to dominate at lower $\mathrm{pH}$ values (Davis et al., 1986b; Henick-Kling, 1993).

When MLF is complete, the remaining LAB are still able to metabolise residual sugar, which could result in spoilage including volatile acidity (Fugelsang \& Edwards, 1997). This is particularly prevalent in high $\mathrm{pH}$ wines, where Lactobacillus and Pediococcus may occur and contribute to wine spoilage (Wibowo et al., 1985). It is therefore imperative to control the potential impact of residual LAB populations after the completion of MLF to reduce the risk of spoilage.

By understanding the evolution of LAB from the vineyard/ grape surfaces, through the different vinification procedures, as well as their metabolic requirements, it is possible to control which species of LAB occur at a particular stage and to ensure that they make a positive contribution during MLF.

\section{Metabolism of lactic acid bacteria}

\section{Metabolism of carbohydrates}

Lactic acid bacteria possess two main pathways for the metabolism of glucose and a single pathway for the metabolism of pentose sugars. The two pathways for the metabolism of glucose include the glycolysis/Embden-Meyerhof-Parnas (EMP) pathway and the 6-phosphogluconate/phosphoketolase (6-PG/PK) pathway (also referred to as the phosphoketolase- or pentose phosphate pathway) (Fugelsang \& Edwards, 1997).

Glucose, as a free sugar, is transported into the cell where it is phosphorylated by hexokinase, a reaction which is ATPdependant, before it enters one of the two mentioned pathways. The EMP pathway, also known as homolactic fermentation in $\mathrm{LAB}$, leads to the formation of lactic acid as the main end-product, as well as the production of $\mathrm{CO}_{2}$. This pathway is divided into two steps. The first reaction is glycolysis, whereby pyruvate is produced from glucose, followed by the conversion of pyruvate to 
produce lactic acid (Ribéreau-Gayon et al., 2006). This pathway is utilised by Pediococcus strains and the metabolism of one mole of glucose produces two moles of lactic acid as well as a net amount of two ATP. The 6-PG/PK pathway, also known as heterolactic fermentation, results in the production of lactic acid and $\mathrm{CO}_{2}$, as well as the end-products ethanol and acetate. Species of LAB that make use of this pathway include all the strains of Leuconostoc, some Lactobacillus strains and O. oeni. One mole of glucose metabolised via this pathway will lead to the formation of equimolar amounts of each of lactic acid, ethanol and $\mathrm{CO}_{2}$, as well as one mole of ATP (Fugelsang \& Edwards, 1997).

Many LAB are able to ferment pentose sugars and special permeases are used for entry of pentose sugar into the cell. Pentoses are phosphorylated, converted by epimerases or isomerases to phosphate derivatives ribulose-5-phosphate or xylulose-5phosphate, after which they are metabolised via the bottom half of the 6-PG/PK pathway. The end-products of pentoses metabolism are equimolar amounts of lactic acid, acetic acid and $\mathrm{CO}_{2}$.

According to the pathway used for the metabolism of carbohydrates, LAB can be divided into three metabolic groups. Each group also differs according to the enzymes that are needed for carbohydrate metabolism. The obligatory homofermentors only make use of the EMP pathway for carbohydrate metabolism. They possess the aldolase enzyme but the phosphoketolase enzyme is absent. All wine Pediococcus species are included in this group. The obligatory heterofermentors include Lactobacillus brevis, Lactobacillus hilgardii, Leuconostoc species and $O$. oeni. This group utilises the 6-PG/PK fermentation pathway for the metabolism of carbohydrates. This group displays phosphoketolase activity but do not possess the aldolase enzyme. Some Lactobacillus species are facultative heterofermentors. These include $L$. casei and $L$. plantarum. These LAB make use of the EMP pathway for hexose metabolism and the 6-PG/PK pathway for the metabolism of pentose sugars and other substrates. These LAB only possess the aldolase enzyme (Fugelsang \& Edwards, 1997).

An understanding of the metabolic requirements of LAB will aid the winemaker in making decisions regarding the nutrient requirements and management during MLF.

\section{INDUCTION OF MALOLACTIC FERMENTATION}

\section{Commercial starter cultures}

Winemakers are starting to recognise the benefits of inoculating grape must or wine with commercial starter cultures of LAB to ensure the successful completion of MLF (Davis et al., 1985; Fugelsang \& Zoecklein, 1993; Henick-Kling, 1995; KriegerWeber, 2009) and to reduce the risks associated with spontaneous MLF. Potential risks include the presence of unidentified/spoilage bacteria that can produce undesirable or off-flavours, the production of biogenic amines (Davis et al., 1985), a delay in the onset or completion of MLF (Nielsen et al., 1996) and the development of bacteriophages (Bauer \& Dicks, 2004); all of which contribute to a decrease in the quality of the wine (Bartowsky \& Henschke, 1995; Fugelsang \& Edwards, 1997). By inoculating with a commercial starter culture, most of which contain $O$. oeni as the single LAB culture, the winemaker can reduce the risk of potential spoilage bacteria or bacteriophages, promote the rapid start and completion of MLF and also encourage a positive flavour contribution by the
LAB (Krieger-Weber, 2009). Recently, L. plantarum has also been considered for application in a commercial starter culture (Bou \& Krieger, 2004).

Lactic acid bacteria strain ML34 served as the prototype in the 1960's to 1970's for the development of the concept of inoculating for MLF with a single strain. Malolactic fermentation starter cultures were available in liquid form and used for decades until the early 1980 's. At that time, frozen and freeze-dried LAB starter cultures were developed. Shortly after, in the 1990's, direct inoculation freeze-dried starter cultures were developed, with Viniflora oenos being the first (Nielsen et al., 1996). Their use has made it easier to control and predict the progression of MLF in wine (Specht, 2006). These commercial cultures are also easy to ship, store and use, which adds to their increasing popularity. A commercial starter culture contains a very high population of viable bacteria, $\pm 10^{11} \mathrm{CFU} / \mathrm{g}$, to ensure that any loss in viability due to the wine conditions is not detrimental to the completion of MLF (Henick-Kling, 1993, 1995). Table 1 gives a general overview of some of the commercial MLF starter cultures that are available at present.

There are various types or forms of $\mathrm{LAB}$ starter cultures available. The liquid suspension culture only has a shelf life of 2 to 20 days and requires a preparation time of 3 to 7 days. The frozen cultures need to be inoculated immediately after being thawed and the pellets are directly added to the wine. To the contrary, the direct inoculation $(\mathrm{MBR} \otimes)$ culture does not need any special preparation and is directly added to the wine.

The quick build-up starter culture (1-STEP $®)$ requires an additional activation step whereby an activator and wine is added to the culture 18 to 24 hours prior to inoculation in the wine. The traditional freeze-dried culture has to be rehydrated in a wine/ water mixture and addition of the culture to the wine takes place over a period of 3 to 14 days.

In an effort to be more cost-effective, a technique referred to as stretching can be implemented. The stretching of starter cultures imply using less than the recommended dosage, but can also imply the re-use of commercial starter cultures as in the case of mother tank inoculation as well as inoculation from the lees of wines that have finished MLF. These are risky practices. There is a possibility of the development of spoilage microorganisms due to the decreased population of inoculated bacteria and MLF may not be successfully completed. Further risks include a lack of control over the MLF process as well as the contamination of further fermentation vessels from a contaminated mother tank (Van der Merwe, 2007). Due to the risks associated with spontaneous or uncontrolled MLF and stretching, it is important for the winemaker to realise the benefits associated with inoculating for MLF with a starter culture as well as inoculating according to the directions of the manufacturer.

The selection and characterisation of strains for possible use in a commercial culture is crucial, due to the fact that LAB strains differ in their fermentation capabilities and growth characteristics (Britz \& Tracey, 1990; Henick-Kling, 1993). Strict criteria are used for the selection of bacteria to be used as starter cultures (Davis et al., 1985; Vaillant et al., 1995; Volschenk et al., 2006; KriegerWeber, 2009). These criteria include the following: tolerance to low $\mathrm{pH}$, high ethanol and $\mathrm{SO}_{2}$ concentrations, good growth characteristics under winemaking conditions, compatibility with 
TABLE 1

A general overview of some of the MLF starter cultures that are available as well as their main characteristics and applications (compiled from company websites).

\begin{tabular}{|c|c|c|c|c|}
\hline Name & Company & Characteristics & Application & Form \\
\hline Viniflora CH16 & Chr. Hansen & $\begin{array}{l}\text { Temperature: } 17-25^{\circ} \mathrm{C} \\
\text { Alcohol tolerance: } 16 \% \cdot \mathrm{pH}: 3.4 \\
\mathrm{TSO}_{2} * \text { tolerance: } 40 \mathrm{ppm}\end{array}$ & $\begin{array}{l}\text { High alcohol red and some } \\
\text { types of rosé wines }\end{array}$ & Frozen/Freeze-dried \\
\hline Viniflora CH35 & Chr. Hansen & $\begin{array}{l}\text { Temperature: } 15-25^{\circ} \mathrm{C} \\
\text { Alcohol tolerance: } 14 \% \text { pH: } 3.1 \\
\mathrm{TSO}_{2} \text { tolerance: } 45 \mathrm{ppm}\end{array}$ & White and some rosé wines & Frozen/Freeze-dried \\
\hline Viniflora CH11 & Chr. Hansen & $\begin{array}{l}\text { Temperature: } 14-25^{\circ} \mathrm{C} \\
\text { Alcohol tolerance: } 15 \% \cdot \mathrm{pH}: 3 \\
\mathrm{TSO}_{2} \text { tolerance: } 35 \mathrm{ppm}\end{array}$ & Low $\mathrm{pH}$ white and some rosé wines & Frozen/Freeze-dried \\
\hline Viniflora oenos & Chr. Hansen & $\begin{array}{l}\text { Temperature: } 17-25^{\circ} \mathrm{C} \\
\text { Alcohol tolerance: } 14 \% \cdot \mathrm{pH}: 3.2 \\
\mathrm{TSO}_{2} \text { tolerance: } 40 \mathrm{ppm}\end{array}$ & Red, rosé and white wines & Frozen/Freeze-dried \\
\hline Viniflora Ciné & Chr. Hansen & $\begin{array}{l}\text { Temperature: } 17-25^{\circ} \mathrm{C} \\
\text { Alcohol tolerance: } 14 \% \cdot \mathrm{pH}: 3.2 \\
\mathrm{TSO}_{2} \text { tolerance: } 30 \mathrm{ppm}\end{array}$ & $\begin{array}{l}\text { Red, rosé and white wines, sparkling } \\
\text { wine with no diacetyl production }\end{array}$ & Frozen \\
\hline Biolact Acclimatée & AEB Group & $\mathrm{NA}^{* *}$ & NA & Freeze-dried \\
\hline Biolact Acclimatée BM & AEB Group & Temperature: $12^{\circ} \mathrm{C} \cdot \mathrm{pH}: 3$ & NA & Freeze-dried \\
\hline Biolact Acclimatée PB1025 & AEB Group & $\begin{array}{l}\text { Temperature: } 15-18^{\circ} \mathrm{C} \\
\text { Alcohol tolerance: high. pH: } 2.9 \\
\mathrm{TSO}_{2} \text { tolerance: high }\end{array}$ & White, rosé and young red wines & Freeze-dried \\
\hline Biolact Acclimatée 4R & AEB Group & $\begin{array}{l}\text { Temperature: resistance to low temp. } \\
\text { Alcohol tolerance: high }\end{array}$ & $\begin{array}{l}\text { Red wines with high tannin } \\
\text { concentrations }\end{array}$ & Freeze-dried \\
\hline Lactoenos B16 Standard & Laffort & $\begin{array}{l}\text { Temperature: }>16^{\circ} \mathrm{C} \\
\text { Alcohol tolerance: } 16 \% \\
\text { pH: }>2.9 \\
\mathrm{TSO}_{2} \text { tolerance: } 60 \mathrm{ppm}\end{array}$ & Acidic white wines & NA \\
\hline Lactoenos SB3 Instant & Laffort & $\begin{array}{l}\text { Temperature: }>16^{\circ} \mathrm{C} \\
\text { Alcohol tolerance: } 15 \% \cdot \mathrm{pH}:>3.3 \\
\mathrm{TSO}_{2} \text { tolerance: } 30 \mathrm{ppm}\end{array}$ & $\begin{array}{l}\text { High quality wines } \\
\text { (undergoing barrel MLF) }\end{array}$ & NA \\
\hline Lactoenos 350 PreAc & Laffort & $\begin{array}{l}\text { Temperature: }>15^{\circ} \mathrm{C} \\
\text { Alcohol tolerance: } 16 \% \cdot \mathrm{pH}:>3 \\
\mathrm{TSO}_{2} \text { tolerance: } 60 \mathrm{ppm}\end{array}$ & Low $\mathrm{pH}$ white and certain rosé wines & NA \\
\hline Lactoenos 450 PreAc & Laffort & $\begin{array}{l}\text { Temperature: }>16^{\circ} \mathrm{C} \\
\text { Alcohol tolerance: } 17 \% \cdot \mathrm{pH}:>3.3 \\
\mathrm{TSO}_{2} \text { tolerance: } 80 \mathrm{ppm}\end{array}$ & Red and white wines & NA \\
\hline 1 Step Alpha & Lallemand & $\begin{array}{l}\text { Temperature: } 14^{\circ} \mathrm{C} \\
\text { Alcohol tolerance: high. pH: }>3.3 \\
\mathrm{TSO}_{2} \text { tolerance: }<40 \text { ppm }\end{array}$ & Red and white wines & Freeze-dried \\
\hline 1 Step VP41 & Lallemand & $\begin{array}{l}\text { Temperature: } 17^{\circ} \mathrm{C} \\
\text { Alcohol tolerance: high. } \mathrm{TSO}_{2} \text { tolerance: } \\
<60 \mathrm{ppm}\end{array}$ & High alcohol red wines & Freeze-dried \\
\hline Enoferm Beta & Lallemand & $\begin{array}{l}\text { Temperature: } 14^{\circ} \mathrm{C} \\
\text { Alcohol tolerance: } 15 \% . \mathrm{pH}:>3.2 \\
\mathrm{TSO}_{2} \text { tolerance: }<60 \mathrm{ppm}\end{array}$ & Red wines & Freeze-dried \\
\hline
\end{tabular}




\section{TABLE 1 (CONTINUED)}

A general overview of some of the MLF starter cultures that are available as well as their main characteristics and applications (compiled from company websites).

\begin{tabular}{|c|c|c|c|c|}
\hline Lalvin 31 & Lallemand & $\begin{array}{l}\text { Temperature: } 13^{\circ} \mathrm{C} \cdot \mathrm{pH}:>3.1 \\
\mathrm{TSO}_{2} \text { tolerance: }<45 \mathrm{ppm}\end{array}$ & Red and white wines & Freeze-dried \\
\hline Lalvin Elios 1 & Lallemand & $\begin{array}{l}\text { Temperature: } 18^{\circ} \mathrm{C} \\
\text { Alcohol tolerance: high. } \mathrm{pH}:>3.4 \\
\mathrm{TSO}_{2} \text { tolerance: }<50 \text { ppm }\end{array}$ & Red wine & Freeze-dried \\
\hline Lalvin ICV Elios Blanc & Lallemand & $\mathrm{pH}:<3.4$ & $\begin{array}{l}\text { White and rosé wines with difficult } \mathrm{pH} \\
\text { and temperature conditions }\end{array}$ & Freeze-dried \\
\hline Lalvin VP41 & Lallemand & $\begin{array}{l}\text { Temperature: } 16^{\circ} \mathrm{C} \\
\text { Alcohol tolerance: excellent. } \mathrm{pH}:>3.1 \\
\mathrm{TSO}_{2} \text { tolerance: }<60 \mathrm{ppm}\end{array}$ & High alcohol red wines & Freeze-dried \\
\hline PN4 & Lallemand & $\begin{array}{l}\text { Temperature: } 16^{\circ} \mathrm{C} \\
\mathrm{pH}:>3 . \mathrm{TSO}_{2} \text { tolerance: }<60 \mathrm{ppm}\end{array}$ & Red and white wines & Freeze-dried \\
\hline Lalvin Bacchus & Lallemand & $\begin{array}{l}\text { Temperature: } 18-24^{\circ} \mathrm{C} \\
\text { Alcohol tolerance: } 13.5 \% \cdot \mathrm{pH}:>3.1\end{array}$ & Red and white wines & Freeze-dried \\
\hline BioStart oenos SK1 & Erbslöh Geisenheim & $\begin{array}{l}\text { Temperature: } 17-25^{\circ} \mathrm{C} \\
\text { Alcohol tolerance: } 13 \% . \mathrm{pH}:>3.1\end{array}$ & Simple-structured red and white wines & NA \\
\hline BioStart Forte SK2 & Erbslöh Geisenheim & $\begin{array}{l}\text { Temperature: } 14-25^{\circ} \mathrm{C} \\
\text { Alcohol tolerance: } 14.5 \% \cdot \mathrm{pH}:>3\end{array}$ & $\begin{array}{l}\text { Red wine but also suited for } \\
\text { white wine }\end{array}$ & NA \\
\hline BioStart Bianco SK3 & Erbslöh Geisenheim & $\begin{array}{l}\text { Temperature: } 13-24^{\circ} \mathrm{C} \\
\text { Alcohol tolerance: } 13.5 \% \cdot \mathrm{pH}:>3\end{array}$ & $\begin{array}{l}\text { White wines with low diacetyl } \\
\text { concentration }\end{array}$ & NA \\
\hline BioStart Vitale SK11 & Erbslöh Geisenheim & $\begin{array}{l}\text { Temperature: }>16^{\circ} \mathrm{C} \\
\text { Alcohol tolerance: } 15.5 \% \cdot \mathrm{pH}:>3 \\
\mathrm{TSO}_{2} \text { tolerance: high }\end{array}$ & Red and white wines & NA \\
\hline
\end{tabular}

\footnotetext{
$*$ Total $\mathrm{SO}_{2}$

** NA: not available
}

Saccharomyces cerevisiae, ability to survive the production process, the inability to produce biogenic amines, the lack of offflavour or off-odour production as well as the production of aroma compounds that could potentially contribute to a favourable wine aroma profile (Wibowo et al., 1985; Kunkee, 1991; Fugelsang \& Zoecklein, 1993; Henick-Kling, 1993; Le Jeune et al., 1995; DriciCachon et al., 1996; Lonvaud-Funel, 2001; Marcobal et al., 2004; Volschenk et al., 2006). Recently, Guzzon et al. (2009) selected a new strain for MLF, using the resistance to low fermentation temperature, high $\mathrm{SO}_{2}$, high ethanol concentration and low $\mathrm{pH}$ as selection criteria. The technological and qualitative properties important in the selection criteria for LAB strains for use in starter cultures for MLF were recently summarised by Krieger-Weber (2009).

The procedure of strain selection is a complex and laborious process that involve various screening procedures and trial vinifications. Lactic acid bacteria are isolated from spontaneous fermentations that have natural selective pressures of low $\mathrm{pH}$, low temperature, high alcohol and high $\mathrm{SO}_{2}$ levels. Individual colonies then undergo vigorous genetic screening to confirm identity, differentiate between strains and determine genetic stability. These strains are then evaluated for their resistance to the physiochemical properties in wine, metabolic properties, nutritional requirements and their ability to survive and retain viability after the drying process. One of the final steps is microvinifications to evaluate the strains under actual winemaking conditions (Bou \& Powell, 2006; Mañes-Lázaro et al., 2008a, 2008b, 2009; Capozzi et al., 2010; Ruiz et al., 2010).

Even with the use of commercial starter cultures, complete and successful MLF is not always guaranteed, especially under very difficult wine conditions (i.e. low $\mathrm{pH}$, high ethanol) (Guerzoni et al., 1995). It is imperative that winemakers follow the directions for the reactivation of freeze-dried starter cultures as recommended by the manufacturer, as this minimises some of the potential loss in viability due to direct inoculation in the wine (Davis et al., 1985; Nault et al., 1995; Nielsen et al., 1996; Volschenk et al., 2006). The success of the inoculated bacterial culture to initiate and successfully complete MLF is also influenced by the timing of inoculation. The winemaker should also consider a commercial starter culture that can tolerate the physiochemical properties of 
the wine to be inoculated as well as the specifications (e.g. the ability to tolerate high alcohol concentrations) of each culture as reported by the manufacturer.

\section{Timing of inoculation}

There are three possible inoculation scenarios for MLF referred to in this review: simultaneous inoculation for AF and MLF (coinoculation), inoculation during $\mathrm{AF}$ and inoculation after the completion of AF (sequential inoculation).

Henick-Kling \& Park (1994) and Alexandre et al. (2004) mentioned the possible risks of simultaneous inoculation as the development of undesirable/antagonistic interactions between yeast and/or bacteria, stuck $\mathrm{AF}$ and the production of possible offodours. In contrast, Jussier et al. (2006) found no negative impact on fermentation success or kinetics associated with simultaneous inoculation, compared to traditional post $\mathrm{AF}$ inoculation and no difference in the final wine quality of cool-climate Chardonnay wines. They propose that simultaneous inoculation can be used as a tool to overcome high ethanol levels and reduced nitrogen content at the end of AF. Zapparoli et al. (2009) investigated the use of acclimatised bacterial cells in co-inoculation and sequential inoculation as a means to induce MLF in high alcohol wines. Co-inoculation of the bacterial cells resulted in complete MLF in a shorter time period compared to that of the sequential inoculation.

During co-inoculation, the simultaneous metabolism of citric acid and glucose could lead to the production of more acetic acid by O. oeni, a heterofermentative LAB (Liu, 2002; Costello, 2006). It has also been shown that wines that have undergone simultaneous $\mathrm{AF} / \mathrm{MLF}$ tend to be less buttery, retain more fruitiness and are therefore more complex and better structured with marginally higher but sensorial insignificant levels of acetic acid (HenickKling, 1993; Bartowsky et al., 2002b; Jussier et al., 2006; Krieger, 2006). Semon et al. (2001) and Jussier et al. (2006) compared co-inoculation with sequential inoculation in Chardonnay wines. Jussier et al. (2006) found no negative impact of simultaneous AF/MLF on the fermentation success or final wine parameters. The sensory panel could not differentiate between wines from the two treatments and, although slightly higher levels of acetic acid were produced in the co-inoculation treatments in both studies, the differences were not statistically relevant and within the range of concentrations normally found in wine. Co-inoculation also had the advantage of reducing overall fermentation duration. Other advantages include more efficient MLF in 'difficult' wines (e.g. low pH) due to low levels of ethanol and higher nutrient concentrations. Wines are also immediately available for racking, fining and $\mathrm{SO}_{2}$ additions (Davis et al., 1985; Jussier et al., 2006). More recent results on co-inoculation, as mentioned above, highlight this practice as a viable option if care is taken regarding the strain selection of both the bacteria and the yeast.

Inoculation during AF is not a common practice and Rosi et al. (2003) reported the strongest antagonism between yeast and bacteria with inoculation of LAB during AF. Bacterial populations showed drastic decreases with this type of inoculation and this could be attributed to various factors including the removal of nutrients by the yeast, accumulation of $\mathrm{SO}_{2}$, ethanol production, toxic metabolite production by the yeast and acid production by the yeast that decrease the $\mathrm{pH}$. The same study found that at the end of AF, yeast presence favoured the growth and malolactic activity of LAB. This could be attributed to yeast autolysis that release vitamins, amino acids, proteins and polysaccharides that stimulate bacterial metabolism (Henick-Kling, 1993). Early results by some authors advocate sequential inoculation as a means to avoid the problems associated with early inoculation (Ribéreau-Gayon, 1985; Henick-Kling, 1993). The advantages of sequential inoculation include the lack of adverse interactions between yeast and bacteria as well as a reduced risk of acetic acid production due to smaller residual sugar concentrations (Costello, 2006). In spite of these advantages, there are still risks related with sequential inoculation and a loss in viability may possibly be attributed to the presence of high ethanol concentrations, low $\mathrm{pH}, \mathrm{SO}_{2}$, other antimicrobial compounds produced by the yeast as well as nutrient depletion (Larsen et al., 2003).

The timing of inoculation therefore merits careful consideration and will ultimately affect the style and quality of the wine. It is clear that the timing of inoculation for MLF and the concomitant interaction between the yeast and bacterial cultures play an important role in the success of MLF.

\section{FACTORS INFLUENCING MALOLACTIC FERMENTATION}

There are various factors that have an effect on $\mathrm{LAB}$ and in turn the successful completion of MLF. These factors may directly influence the growth or affect the metabolic properties of LAB. These include $\mathrm{pH}$, temperature, ethanol, $\mathrm{SO}_{2}$, as well as other products related to yeast metabolism.

Kunkee (1991) listed temperature, ethanol, $\mathrm{pH}$ and $\mathrm{SO}_{2}$ as the four major parameters that would influence the commencement and rate of MLF. This was confirmed by Vaillant et al. (1995) that found the same four parameters had the largest inhibitory effect on the malolactic activity of three $O$. oeni strains and three L. plantarum strains. Gockowiak \& Henschke (2003) suggested that LAB culture viability may be more significantly affected by the wine matrix than wine parameters like $\mathrm{pH}$ and ethanol. In addition, it is not only the individual effects of the different factors that have to be taken into account, but the interactive and synergistic effects are also to be considered. These influencing factors do not only affect the growth and the malolactic activity of $\mathrm{LAB}$, but also influence the effect that the LAB will have on wine aroma. Delaquis et al. (2000) saw changes in the wine chemistry and aroma characteristics in Chancellor wines and attributed this to the interaction between the LAB culture, yeast strain and fermentation temperature.

From these findings it is clear that there are a selection of factors to consider, including their interactions and the effect of the wine matrix. The following factors will be discussed in more detail: the interaction between yeast ( $S$. cerevisiae) and bacteria, yeast-related metabolic products including ethanol and medium chain fatty acids as well as physiochemical wine parameters like $\mathrm{pH}$, temperature and $\mathrm{SO}_{2}$, the presence of various phenolic compounds, the addition of lysozyme as well as a brief overview of the influence that different vinification procedures have on LAB.

\section{Yeast-bacteria interactions}

A factor that the winemaker has the most control over is the selection of the yeast and bacterial culture for AF and MLF, respectively. The interaction between bacteria and yeast during AF and/or MLF will have a direct effect on LAB growth and malolactic activity. Various studies have been done to attempt 
an understanding of the interaction between yeast and bacteria (Henick-Kling \& Park, 1994; Rosi et al., 2003; Arnink \& HenickKling, 2005; Guilloux-Benatier et al., 2006; Jussier et al., 2006; Osborne \& Edwards, 2006), with a comprehensive review of the possible interactions by Alexandre et al. (2004).

Alexandre et al. (2004) proposed that the degree and complexity of these interactions are due to three factors. Firstly, the combination of yeast and bacteria strain. In a recent study by Nehme et al. (2008) on the interactions between $S$. cerevisiae and $O$. oeni during the winemaking process, it was found that the extent to which inhibition between these microorganisms occur is largely dependent on the selected strains of yeast and bacteria and that the inhibition correlated to a decrease in bacterial growth, rather than a decline in the malolactic activity of the bacteria. In contrast, Arnink \& Henick-Kling (2005) in a study of commercial pairings of $O$. oeni and $S$. cerevisiae, found the differences between vintages and grape varieties to be more influential on LAB and MLF than the effect of a particular yeast/bacteria strain combination.

Costello et al. (2003) proposed a method for testing the compatibility between yeast and bacteria. The aim of the study was to investigate the interaction between these two microorganism populations without the effect of extrinsic grapederived or processing factors like $\mathrm{SO}_{2}$ additions, modified $\mathrm{pH}$, sugar concentration and the presence of pesticide residues or nutrients. A chemically defined medium was used to successfully characterise the metabolic interactions between the yeast and bacteria and replacement of the synthetic media with Chardonnay juice produced similar results. This could be an effective tool for screening yeast/LAB combinations in advance to ensure compatibility and lack of antagonistic or inhibitory effects. The winemaker also has control over the vinification practices applied during the winemaking process. These decisions can also affect the interaction between the bacteria and yeast culture. Table 2 shows the effect that different vinification procedures and decisions have on $\mathrm{LAB}$ as well as yeast/bacteria interactions.

The second factor is the uptake and release of nutrients by the yeast, which will in turn affect the nutrients available for the LAB. At the start of AF, O. oeni is inhibited by $S$. cerevisiae due to the rapid uptake of certain grape metabolites from the must by the yeast. These compounds include sterols, amino acids and vitamins (Larsen et al., 2003), which result in a nutrient diminished environment for the bacteria. During AF the amino acids and vitamins that are essential for bacterial proliferation are depleted by yeast metabolism to such an extent, that the commencement of bacterial growth is delayed until yeast cells lyse (Nygaard \& Prahl, 1997; Alexandre et al., 2004; Arnink \& Henick-Kling, 2005). Yeast autolysis plays a vital role in the release of essential nutrients for LAB proliferation and survival (Alexandre et al., 2004). Yeast autolytic activity can release amino acids, peptides, proteins, glucans and mannoproteins and release of these macromolecules are yeast strain dependant (Alexandre et al., 2001, 2004). Mannoproteins seem to be of significant importance, as their release can stimulate bacterial growth by adsorbing medium chain fatty acids and thus detoxifying the wine medium. Mannoproteins can also be enzymatically hydrolysed by bacterial enzyme activity, which will enhance the nutritional content of the wine and in turn stimulate bacterial growth (Guilloux-Benatier \&
Chassagne, 2003; Alexandre et al., 2004). Yeast metabolism has a direct effect on the nitrogen concentration available for LAB consumption. This was recently confirmed by Guilloux-Benatier et al. (2006), who found that proteolytic activity by yeast can affect the nitrogen composition of wine after AF, which in turn will affect the ability of $O$. oeni to grow and complete MLF.

Information on the specific nitrogen compounds that are yeastderived and that are actually of importance to LAB metabolism, besides amino acids, are limited (Alexandre et al., 2001). It is therefore necessary to identify the essential nutrients for which both LAB and yeast compete and to quantify these compounds to ensure the viability and growth of these microorganisms (Arnink \& Henick-Kling, 2005). Metabolic compounds that still warrant further investigation as to their exact role in yeast-bacteria interactions and LAB growth stimulation include vitamins, nucleotides and lipids released by the yeast.

Comitini et al. (2005) related part of the inhibitory effect of $S$. cerevisiae to the production of extracellular compounds via metabolic activity of the yeast, rather than a competition for nutrients. Therefore, the third factor to consider is the ability of the yeast to produce metabolites that can either have a stimulatory or inhibitory/toxic effect on LAB. There are a number of yeastderived inhibitory compounds, including ethanol, $\mathrm{SO}_{2}$, medium chain fatty acids and proteins. The first three are the compounds most commonly studied with regards to LAB growth inhibition (Alexandre et al., 2004). Osborne \& Edwards (2006) found a peptide produced by $S$. cerevisiae inhibited $O$. oeni and that this inhibition is dependent on the presence of $\mathrm{SO}_{2}$. This study was performed in synthetic medium and the proposed mechanism was the possible disruption of the cell membrane. Similarly, Comitini et al. (2005) also reported a LAB inhibitory compound produced by yeast to be heat and protease sensitive and therefore also of a proteinaceous nature. In a similar study, Nehme et al. (2010) reported the inhibition of an $O$. oeni strain by $S$. cerevisiae that resulted in a decrease in the malic acid consumption by the LAB strain. This inhibition could be attributed, in part, to a peptidic fraction produced by the yeast. Table 3 provides a summary of the major inhibitory compounds produced by yeast.

To add to the complexity of these interactions, some yeast strains can be both stimulatory and inhibitory, certain LAB strains are capable of inhibiting wine yeast and the composition of the must, as well as vinification practices, influence the interaction.

\section{Ethanol}

Ethanol is the main yeast metabolite formed during AF and due to its adverse effect on LAB growth and metabolic activity, plays an integral role in the ability of LAB to survive in the wine environment and accomplish MLF. As with most LAB inhibitory factors, ethanol also demonstrates synergistically inhibiting effects with temperature. The optimal growth temperature of LAB decrease at high ethanol concentrations and elevated temperatures lower the ability of LAB to withstand increased ethanol concentrations (Henick-Kling, 1993; Bauer \& Dicks, 2004). Temperatures of $25^{\circ} \mathrm{C}$ and above, combined with ethanol levels of 10 to $14 \%(\mathrm{v} / \mathrm{v})$, almost completely inhibit LAB growth and optimum growth at these ethanol levels occur between 18 and $20^{\circ} \mathrm{C}$ (Henick-Kling, 1993). Capucho \& San Ramao (1994) documented no inhibition of the malolactic activity of $O$. oeni with ethanol levels of up to $12 \%(\mathrm{v} / \mathrm{v})$, but saw an inverse correlation between the growth of 
TABLE 2

The influence of different winemaking practices on LAB growth (compiled from Edwards et al., 1990 and Alexandre et al., 2004).

\begin{tabular}{ll}
\hline Practice & Influence \\
\hline Degree of must clarification & Significant impact on bacterial growth. Yeast produce more medium chain fatty acids in highly clarified must \\
Skin contact prior to AF & Direct effect on extraction of nitrogenous and other macromolecules Stimulate LAB growth and malolactic activity \\
Choice of yeast strain & Inhibitory and stimulatory effects differ between strains \\
Ageing of wine on yeast lees & Yeast autolysis release nutrients that stimulate LAB growth and malolactic activity \\
\hline
\end{tabular}

\section{TABLE 3}

Yeast activity inhibiting $\mathrm{LAB}$ via the production of yeast metabolites.

\begin{tabular}{|c|c|c|}
\hline Yeast metabolite & Effect on LAB and/or MLF & Reference \\
\hline Ethanol & Affect growth ability rather than malolactic activity & Alexandre et al. (2004) \\
\hline $\mathrm{SO}_{2}$ & $\mathrm{AF}$ with $\mathrm{SO}_{2}$ producing yeast strain results in wine inhibitory to MLF & $\begin{array}{l}\text { Henick-Kling \& Park (1994) } \\
\text { Alexandre et al. (2004) }\end{array}$ \\
\hline Medium chain fatty acids & $\begin{array}{l}\text { Affect LAB growth and reduce ability to metabolise malic acid. Combination of } \\
\text { fatty acids (hexanoic, octanoic and decanoic acid) cause greater inhibition than } \\
\text { individual compounds. }\end{array}$ & $\begin{array}{l}\text { Alexandre et al. }(2004) \\
\text { Edwards et al. }(1990) \\
\text { Lonvaud-Funel } \text { et al. }(1988)\end{array}$ \\
\hline Metabolites of protein nature & $\begin{array}{l}\text { Peptide produced by } S \text {. cerevisiae during AF: inhibit } O \text {. oeni by disruption of cell } \\
\text { membrane; inhibition dependant on } \mathrm{SO}_{2}\end{array}$ & $\begin{array}{l}\text { Osborne \& Edwards (2006) } \\
\text { Nehme } \text { et al. (2010) }\end{array}$ \\
\hline
\end{tabular}

O. oeni and increasing ethanol concentrations (Davis et al., 1988; Henick-Kling, 1993; Alexandre et al., 2004; Bauer \& Dicks, 2004).

It is generally acknowledged that $O$. oeni strains are able to survive and proliferate in $10 \%(\mathrm{v} / \mathrm{v})$ ethanol at $\mathrm{pH} 4.7$ (Britz \& Tracey, 1990). G-Alegría et al. (2004) reported the ability of O. oeni and L. plantarum strains to grow at $13 \%(\mathrm{v} / \mathrm{v})$ ethanol and Henick-Kling (1993) stated that ethanol concentrations exceeding $14 \%(\mathrm{v} / \mathrm{v})$ inhibit the growth of $O$. oeni. The degree to which LAB are able to tolerate ethanol concentrations are strain dependant, as well as being contingent upon the activation steps before inoculation in the wine (Britz \& Tracey, 1990).

Chu-Ky et al. (2005) investigated the effects of combined cold, acid and ethanol shock on the physical state of the cell membrane and survival of $O$. oeni. Ethanol shocks (10 to $14 \% \mathrm{v} / \mathrm{v}$ ) resulted in instantaneous membrane fluidisation followed by rigidification and a decrease in cell viability, whereas the combined ethanol and acid shock of $10 \%(\mathrm{v} / \mathrm{v})$ and $\mathrm{pH} 3.5$, respectively, resulted in total cell death. In the presence of high concentrations of ethanol the bacteria respond by attempting to maintain the fluidity and integrity of the cell membrane (Couto et al., 1996).

Zapparoli et al. (2009) investigated a possible strategy to conduct MLF in wines that generally do not support MLF due to high ethanol concentrations. The study was performed in Amerone wines with an alcohol content of up to $16 \%$ (v/v) and both coinoculation and sequential inoculation were investigated. Complete degradation of L-malic acid was observed with the use of a starter preparation consisting of bacterial cells that were acclimatised in a wine/water mixture for 48 hours prior to inoculation in the wine. Despite the fact that complete MLF occurred under both inoculation scenarios, the sequential inoculated wine took 112 days to complete MLF, compared to 70 days for co-inoculation. Co-inoculation of high alcohol wines with acclimatised bacterial cells could be a valid strategy for conducting complete MLF in potential high alcohol wines, especially in warmer wine regions like South Africa where grapes are harvested with higher sugar concentrations.

The ability of LAB to tolerate elevated concentrations of ethanol is dependant on a number of factors, including temperature and strain selection.

\section{Sulphur dioxide}

The addition of $\mathrm{SO}_{2}$ at crushing and at later stages in the vinification process is an acceptable method for the inhibition and control of microbial populations (Fleet \& Heard, 1993). Sulphur dioxide exists in various forms in equilibrium in the wine environment including bound $\mathrm{SO}_{2}$, molecular or free $\mathrm{SO}_{2}$ and bisulphite $\left(\mathrm{HSO}_{3}^{-1}\right)$ and sulphite $\left(\mathrm{SO}_{3}^{-2}\right)$ ions (Fugelsang \& Edwards, 1997). The equilibrium of the various $\mathrm{SO}_{2}$ forms is $\mathrm{pH}$-dependant. At low $\mathrm{pH}$, free $\mathrm{SO}_{2}$ predominates, consisting mainly of bisulphite and a small fraction of molecular $\mathrm{SO}_{2}$ and sulphite anions (Usseglio-Tomasset, 1992; Bauer \& Dicks, 2004). Molecular $\mathrm{SO}_{2}$ is considered to be the most inhibitory form, most effective at lower $\mathrm{pH}$ values and the only form of $\mathrm{SO}_{2}$ that can cross bacterial cell walls via diffusion. Inside the cells, the molecular $\mathrm{SO}_{2}$ is converted to bisulphite and may react with various cell components like proteins and affect the growth of LAB (Carreté et al., 2002; Bauer \& Dicks, 2004). Nielsen et al. (1996) found that the combination of low $\mathrm{pH}(\mathrm{pH} 3.2)$ and high $\mathrm{SO}_{2}$ concentration $(26 \mathrm{mg} / \mathrm{L})$ had a strong inhibitory effect on freeze-dried $O$. oeni starter cultures.

The mechanism by which $\mathrm{SO}_{2}$ inhibit $\mathrm{LAB}$ include the rupturing of disulphide bridges in proteins as well as reacting 
with cofactors like $\mathrm{NAD}^{+}$and $\mathrm{FAD}$, thereby affecting the growth of LAB (Romano \& Suzzi, 1993; Carreté et al., 2002). The antimicrobial activity of $\mathrm{SO}_{2}$ can also influence the malolactic activity (Fornachon, 1963; Wibowo et al., 1985; Henick-Kling, 1993; Lonvaud-Funel, 1999). It has recently been shown that $\mathrm{SO}_{2}$ is able to inhibit the ATPase activity which is essential in the maintenance of the intracellular $\mathrm{pH}$ and therefore $\mathrm{LAB}$ growth (Koebmann et al., 2000; Carreté et al., 2002). It has been reported that molecular $\mathrm{SO}_{2}$ concentrations as low as $0.1-0.15 \mathrm{mg} / \mathrm{L}$ may be inhibitory to the growth of some strains. A total $\mathrm{SO}_{2}$ and bound $\mathrm{SO}_{2}$ concentration of less than $100 \mathrm{mg} / \mathrm{L}$ and $50 \mathrm{mg} / \mathrm{L}$ respectively are recommended to ensure successful MLF (Rankine et al., 1970; Powell et al., 2006).

There are various compounds, primarily carbonyl compounds, including acetaldehyde, $\alpha$-ketoglutaric acid and pyruvic acid, that are able to bind $\mathrm{SO}_{2}$ resulting in the bound form which demonstrates weaker antimicrobial activity (Henick-Kling, 1993). Besides being sensitive to inhibition by the molecular form of $\mathrm{SO}_{2}$, LAB also possess the ability to liberate $\mathrm{SO}_{2}$ from acetaldehydebounded sulphur, which then prevents further growth of the bacteria and could result in stuck or sluggish MLF (Fornachon, 1963; Osborne et al., 2006).

LAB species also differ in their ability to tolerate $\mathrm{SO}_{2}$. Both Davis et al. (1988) and Larsen et al. (2003) found that $O$. oeni strains were less tolerant to high total $\mathrm{SO}_{2}$ concentrations than strains of Pediococcus.

Besides the addition of $\mathrm{SO}_{2}$ as part of the vinification process, yeasts are also able to produce significant amounts of $\mathrm{SO}_{2}$ (King \& Beelman, 1986). This ability is dependent on both the media composition as well as the selected yeast strain (Romano \& Suzzi, 1993). Most strains produce less than $30 \mathrm{mg} / \mathrm{L}$, although some strains are able to produce, in extreme cases, more than $100 \mathrm{mg} / \mathrm{L}$ (Suzzi et al., 1985). Henick-Kling \& Park (1994) found that the yeast strains used in their study were able to contribute maximum $\mathrm{SO}_{2}$ levels of between 13 and $42 \mathrm{mg} / \mathrm{L}$ to the total $\mathrm{SO}_{2}$ concentration, of which the larger amounts had a strong inhibitory effect on LAB growth. In a similar study conducted in Chardonnay, Larsen et al. (2003) investigated different wine yeast strains for their ability to inhibit $O$. oeni strains. Yeast strains in this study produced $\mathrm{SO}_{2}$ concentrations ranging from less than $15 \mathrm{mg} / \mathrm{L}$ to $75 \mathrm{mg} / \mathrm{L}$ of total $\mathrm{SO}_{2}$. The yeast also produced very little or no free $\mathrm{SO}_{2}$. The wines containing higher concentrations of total $\mathrm{SO}_{2}$ were still generally more inhibitory towards O. oeni. Due to the low levels of free $\mathrm{SO}_{2}$ produced by the yeast, this research suggests that the remaining fraction of bound $\mathrm{SO}_{2}$ may be more inhibitory than previously considered.

Due to the large influence of wine $\mathrm{pH}$ and individual strain tolerance to $\mathrm{SO}_{2}$, the effect of different $\mathrm{SO}_{2}$ concentrations is diverse. The type of $\mathrm{SO}_{2}$ present (free or bound) also influences the effect on $\mathrm{LAB}$, be it a reduction in malolactic activity or a reduction in LAB growth. Henick-Kling (1993) reported a 13\% reduction in malolactic activity with $20 \mathrm{mg} / \mathrm{L}$ of bound $\mathrm{SO}_{2}$, a $50 \%$ reduction at $50 \mathrm{mg} / \mathrm{L}$ and no malolactic activity at 100 $\mathrm{mg} / \mathrm{L}$ of bound $\mathrm{SO}_{2}$, while a concentration of $30 \mathrm{mg} / \mathrm{L}$ bound $\mathrm{SO}_{2}$ delayed $\mathrm{LAB}$ growth. Lower concentrations of free $\mathrm{SO}_{2}$ are needed for the inhibition of LAB. In results published by Guzzo et al. (1998), O. oeni died within 3 hours in $15 \mathrm{mg} / \mathrm{L}$ of free $\mathrm{SO}_{2}$, whereas Carreté et al. (2002) found that a free $\mathrm{SO}_{2}$ concentration of $20 \mathrm{mg} / \mathrm{L}$ inhibited LAB ATPase activity by more than $50 \%$ and MLF took 40 days to complete in the presence of $5 \mathrm{mg} / \mathrm{L}$ free $\mathrm{SO}_{2}$.

For the control and inhibition of LAB, Henick-Kling (1993) suggests maintaining levels of free $\mathrm{SO}_{2}$ above $10 \mathrm{mg} / \mathrm{L}$ and a total $\mathrm{SO}_{2}$ concentration of above $30 \mathrm{mg} / \mathrm{L}$. Due to the crucial effect that $\mathrm{pH}$ has on the form of $\mathrm{SO}_{2}$ present, García-Ruiz et al. (2008) recommend the following concentrations of free $\mathrm{SO}_{2}$ to inhibit LAB: 10 to $30 \mathrm{mg} / \mathrm{L}$ for $\mathrm{pH} 3.2$ to $3.6,30$ to $50 \mathrm{mg} / \mathrm{L}$ for $\mathrm{pH} 3.5$ to 3.7 and $100 \mathrm{mg} / \mathrm{L}$ for wines with a $\mathrm{pH}$ of over 3.7 .

It is essential for the winemaker to not only take the $\mathrm{SO}_{2}$ added at different stages of the winemaking process into consideration, but also the possible levels of $\mathrm{SO}_{2}$ produced by the yeast, particularly if MLF is required. The combined $\mathrm{SO}_{2}$ concentration from these two sources will influence bacterial survival and proliferation as well as MLF initiation (Henick-Kling \& Park, 1994; Alexandre et al., 2004). It is important to choose a yeast strain that does not produce significant amounts of $\mathrm{SO}_{2}$, and if sulphur is required, then only make small additions at crushing. If larger amounts ( $>30 \mathrm{mg} / \mathrm{L})$ of sulphur is required (e.g. damaged grapes), then MLF inoculation should take place after AF has been completed (Henick-Kling \& Park, 1994).

\section{Medium chain fatty acids}

Lonvaud-Funel et al. (1988) identified medium chain fatty acids (hexanoic, octanoic, decanoic, dodecanoic acid) as one of the main inhibitory products to bacterial growth and MLF formed by yeast metabolism. The inhibitory effects of medium chain fatty acids are highly dependent on the concentration and type of fatty acid (Capucho \& San Ramao, 1994; Lonvaud-Funel et al., 1998; Carreté et al., 2002), the choice of both the yeast and bacteria strains (Nygaard \& Prahl, 1997) as well as the wine pH, with medium chain fatty acids being more inhibitory at lower $\mathrm{pH}$ values (Capucho \& San Ramao, 1994; Alexandre et al., 2004).

Medium chain fatty acids have an inhibitory effect on cell growth of LAB and thus the ability of LAB to metabolise malic acid, which in turn leads to an increase in the duration of MLF. The fatty acids inhibit the ATPase activity of LAB and thereby reduce the ability of the bacteria to maintain the intracellular $\mathrm{pH}$ and transmembrane proton gradient which is essential for the transport of metabolites across the cell membrane (Capucho \& San Ramao, 1994; Carreté et al., 2002).

Lonvaud-Funel et al. (1988) found decanoic acid to be inhibitory to both yeast and bacteria and cause yeast-bacteria antagonism, while Carreté et al. (2002) reported dodecanoic acid to have the biggest inhibitory effect against $O$. oeni. According to Capucho \& San Ramao (1994), decanoic concentrations of above $12.5 \mathrm{mg} / \mathrm{L}$ and dodecanoic concentrations of more than $2.5 \mathrm{mg} / \mathrm{L}$ inhibited $O$. oeni. Decanoic and dodecanoic acids at concentrations below $12.5 \mathrm{mg} / \mathrm{L}$ and $2.5 \mathrm{mg} / \mathrm{L}$, respectively, had a stimulating effect on bacterial growth. In a study by Nehme et al. (2008), none of the four yeast strains they studied were able to produce significant levels of medium chain fatty acids. The highest concentrations produced were $24.8 \mathrm{mg} / \mathrm{L}$ of octanoic acid, $2.9 \mathrm{mg} / \mathrm{L}$ of decanoic acid and $0.2 \mathrm{mg} / \mathrm{L}$ dodecanoic acid, which are far below the inhibitory concentrations reported by Capucho \& San Ramao (1994).

Selection of the most suitable yeast strain is imperative to the eventual success of MLF in wine. Care should be taken to choose 
a yeast strain that is compatible with the strain of $\mathrm{LAB}$, resulting in no or very little antagonistic effects between the yeast/bacteria pairing. This includes a yeast strain that produces very low levels of $\mathrm{SO}_{2}$ and medium chain fatty acids.

\section{pH}

The $\mathrm{pH}$ of the wine plays a crucial role in determining the success of MLF. Wines with a $\mathrm{pH}$ of 3.3 or higher tend to be less problematic in terms of LAB growth and survival as well as MLF, compared to wines with a lower $\mathrm{pH}$. The LAB species that survive and proliferate in the wine is directly dependant on the $\mathrm{pH}$ of the wine (Kunkee, 1967). A pH of 3.5 or lower has a tendency to favour the growth of $O$. oeni and wines with $\mathrm{pH}$ levels higher than 3.5, generally favour the growth of Lactobacillus and Pediococcus species. A pH of less than 3.2 has been shown to be inhibitory to the survival of O. oeni (Henick-Kling, 1993). This could be problematic in cooler climate regions where the $\mathrm{pH}$ can vary between 2.8 and 3.2 (Liu, 2002).

The wine $\mathrm{pH}$ also has a direct effect on the growth rate of bacteria (Kunkee, 1967), with Davis et al. (1986a) reporting the inhibition of sugar metabolism and growth of $O$. oeni at low $\mathrm{pH}$. Although the optimum $\mathrm{pH}$ for the growth of $O$. oeni is $\mathrm{pH} 4.3$ to 4.8, G-Alegría et al. (2004) found that $O$. oeni and L. plantarum are able to grow at $\mathrm{pH} 3.2$. Besides influencing bacterial growth, bacterial viability is also affected by wine $\mathrm{pH}$. Gockowiak \& Henschke (2003) found a pH of 2.9 to 3.5 to have the largest effect on the bacterial viability of commercial starter cultures of $O$. oeni, similar to Rosi et al. (2003) who found that $\mathrm{pH} 3.2$ reduced the bacterial viability of a strain of $O$. oeni. Contrary to these results, Chu-Ky et al. (2005) found that, although acid shocks with $\mathrm{pH}$ levels of 3 to 4 had an effect on the cell membrane, it did not affect the viability of $O$. oeni. A further effect of $\mathrm{pH}$ is the influence on malolactic activity (Henick-Kling, 1993), with the highest malolactic activity seen between $\mathrm{pH} 3.5$ and 4 (Bauer \& Dicks, 2004). The $\mathrm{pH}$ is also critical to the commencement of MLF as well as the time taken to complete MLF (Rosi et al., 2003). Rosi et al. (2003) investigated the effect of $\mathrm{pH}$ on $O$. oeni and found the time it took to complete MLF increased with a decrease in $\mathrm{pH}$, with MLF at pH 3.2 and 3.4 taking 15 to 20 days to complete compared to 10 days at $\mathrm{pH} 3.6$.

It is clear that the $\mathrm{pH}$ of the wine has a number of decisive affects on MLF and LAB. Besides the direct influence of $\mathrm{pH}$, the relationship between $\mathrm{pH}$ and $\mathrm{SO}_{2}$, as previously discussed, is also crucial in understanding the affect of these parameters on the survival of LAB in wine. Lactic acid bacteria also differ in their ability to tolerate and survive at low $\mathrm{pH}$ conditions normally found in wine.

\section{Temperature}

Britz \& Tracey (1990) investigated the influence of certain factors on the growth of 54 strains of LAB and found that temperature had a profound effect on bacterial growth; ethanol showed the greatest inhibitory effect but there was also a synergistic inhibitory effect in the presence of both ethanol and $\mathrm{SO}_{2}$.

Temperature is a parameter that is easy to monitor and control, while having a distinct effect on the ability of LAB to survive in wine as well as to initiate and complete MLF. Temperature affects the growth rate, length of the lag phase and population numbers of LAB (Henick-Kling, 1993; Bauer \& Dicks, 2004).
The optimum growth temperature for $O$. oeni is reported as 27 to $30^{\circ} \mathrm{C}$, but due to the presence of alcohol in wine, the optimum growth temperature in wine decreases to between 20 and $23^{\circ} \mathrm{C}$ (Britz \& Tracey, 1990; Henick-Kling, 1993; Bauer \& Dicks, 2004; Ribérau-Gayon et al., 2006). The optimum temperature for both $O$. oeni growth as well as malic acid metabolism in wine is $20^{\circ} \mathrm{C}$ (Ribérau-Gayon et al., 2006). G-Alegría et al. (2004) found that both $O$. oeni and L. plantarum are able to survive at $18^{\circ} \mathrm{C}$, but temperatures below $18^{\circ} \mathrm{C}$ delay the onset of MLF and increase the duration of MLF, whereas temperatures below $16^{\circ} \mathrm{C}$ inhibit the growth of $O$. oeni as well as leading to a decrease in cellular activity (Henick-Kling, 1993; Ribérau-Gayon et al., 2006). While lower temperatures (below $16^{\circ} \mathrm{C}$ ) decrease cellular activity, ChuKy et al. (2005) found that although cold shocks $\left(8\right.$ and $\left.14^{\circ} \mathrm{C}\right)$ affected the plasma membrane, it did not effect cell survival.

To ensure the rapid initiation and completion of MLF, it is essential to control the fermentation temperature. The fermentation temperature during MLF should be kept at 18 to $22^{\circ} \mathrm{C}$ to ensure optimum malolactic activity of the LAB.

\section{Nutritional requirements}

Besides physiochemical parameters like ethanol, $\mathrm{pH}, \mathrm{SO}_{2}$ and temperature, the nutritional status of the wine is crucial in determining the success of LAB in carrying out MLF and the availability of certain nutrients are therefore imperative (Fugelsang \& Edwards, 1997; Théodore et al., 2005). Lactic acid bacteria have been described as 'fastidious' with regards to their nutritional requirements as a result of their limited biosynthetic capabilities (Fugelsang \& Edwards, 1997; Théodore et al., 2005; Terrade et al., 2009). One of the main components that play a role in LAB survival is the presence of amino acids and due to the incomplete amino acid biosynthetic ability in LAB, the systems that are responsible for amino acid release via protein hydrolysis, is well developed. It has been shown that LAB are able to release essential amino acids to meet survival- and growth requirements (Matthews et al., 2004). This is an important characteristic seeing as LAB are not able to utilise diammonium phosphate as nitrogen source (Fugelsang \& Edwards, 1997). Several essential amino acids have been identified, including glutamic acid, valine, arginine, leucine, isoleucine, as well as cysteine and tyrosine. These may differ according to the bacterial strain (Garvie, 1967; Fugelsang \& Edwards, 1997). Earlier studies also identified nicotinic acid, riboflavin, pantothenic acid and either thiamine/ pyridoxine as being essential to bacterial growth. Many species also require purines and folic acid (Du Plessis, 1963; Fugelsang $\&$ Edwards, 1997). A recent study by Terrade \& Mira de Orduña (2009) investigated the essential nutrient requirements of LAB strains from the Oenococcus and Lactobacillus genera. It was found that 10 compounds were essential for the growth of all the tested strains and that the essential nutrient requirements are strain specific. These 10 compounds include the carbon and phosphate source, manganese and in accordance with other authors, several amino acids and vitamins. The 'tomato-juice factor' has also been described in literature (Garvie \& Mabbitt, 1967). This compound has been described as a derivative of pantothenic acid and although it has not been shown to be essential for all LAB strains, slower bacterial growth has been reported in the absence of this factor (Amachi, 1975; Tracey \& Britz, 1987; Fugelsang \& Edwards, 1997). 
Wines with a low nutrient status will encumber bacterial growth. This situation can be exacerbated by the addition of a yeast strain with a high nutrient demand as well as the fact that certain yeast strains may be prone to producing higher $\mathrm{SO}_{2}$ concentrations in a nutrient deficient environment (Théodore et al., 2005). It has been proposed that co-inoculation of a malolactic starter culture or the addition of a bacterial nutrient could potentially overcome these difficulties. Strain selection of both the yeast and bacterial culture could be an essential tool to ward of future problems with regards to the nutritional status of the grape must or wine (Jussier et al., 2006).

\section{Phenolic compounds}

The major phenolic compounds present in grapes and wine include the non-flavonoids and flavonoids. The non-flavonoids consist of the benzoic- and cinnamic acids and their esters. The flavonoids include the anthocyanins, flavanols, flavan-diols and flavonols (Cheynier et al., 2006).

The amount of phenolics present in wine is cultivar specific as well as being dependant on the vinification procedures implemented by the winemaker (Rozès et al., 2003). The interaction between LAB and phenolic compounds is influenced by various factors including the strain of LAB (Hernández et al., 2007; García-Ruiz et al., 2008) and the type and concentration of phenolic compounds present in the wine (Stead, 1993; Reguant et al., 2000; García-Ruiz et al., 2008). Due to this interaction, phenolic compounds can affect the occurrence as well as rate of MLF (Vivas et al., 1997). Polyphenolic compounds can be transformed by LAB and clear differences in the phenolic content as a result of MLF have been reported (Hernández et al., 2007). The main compounds that can be transformed by different LAB include hydroxycinnamic acids and their derivatives, flavonols and their glycosides, flavanol monomers and oligomers, as well as trans-resveratrol and its glucoside (Hernández et al., 2006, 2007).

Hernández et al. (2006) investigated the effect of MLF on phenolic compounds in red wine and linked the changes to the metabolism of LAB. The LAB in this study exhibited cinnamoyl esterase activity during MLF with a decrease in the concentration of trans-caftaric and trans- $\rho$-coutaric acids resulting in a concomitant increase in the corresponding free forms, transcaffeic and trans- $\rho$-coumaric acids (hydroxycinnamic acids), respectively. Similarly, Cabrita et al. (2008) found that the disappearance of hydroxycinnamoyltartaric acids resulted in an increase in the free forms during both spontaneous and inoculated MLF.

Phenolic compounds can affect bacterial metabolism (Vivas et al., 1997; Rozès et al., 2003), where some phenolic acids inhibit the growth of LAB (Reguant et al., 2000) while others stimulate O. oeni (Vivas et al., 1997). García-Ruiz et al. (2008) reported the metabolism by $\mathrm{LAB}$ of 100 to $250 \mathrm{mg} / \mathrm{L}$ of phenolic compounds before inhibition by concentrations exceeding $500 \mathrm{mg} / \mathrm{L}$. Reguant et al. (2000) found hydroxycinnamic acids to be inhibitory at high concentrations causing MLF to be delayed by $\rho$-coumaric acid at concentrations of more than $100 \mathrm{mg} / \mathrm{L}$ and ferulic acid at concentrations of more than $500 \mathrm{mg} / \mathrm{L}$. Similarly, García-Ruiz et al. (2008) reported the use of free hydroxycinnamic acids as a way of controlling L. plantarum growth and found ferulic acid to be more inhibitory than $\rho$-coumaric acid, whilst the esters of ferulic acid did not affect growth. Vivas et al. (1997) found a slight inhibitory effect on $O$. oeni by vanillic acid, while protocatechuic acid had no effect.

Although the mechanisms by which phenolic compounds inhibit LAB are not entirely clear, there has been some speculation. Possible mechanisms are based on the interactions of phenolic compounds with cellular enzymes (Campos et al., 2003; GarcíaRuiz et al., 2008) and the adsorption of phenols to cell walls (Campos et al., 2003). Phenolic compounds could lead to a loss in potassium ions, glutamic acid and intracellular RNA, as well as causing a change in the composition of fatty acids (Rozès \& Perez, 1998; García-Ruiz et al., 2008). Certain characteristics of wine LAB, like the production of volatile acids and the malolactic activity, are differently affected by the presence of phenolics, and this is dependent on the bacterial strain (Campos et al., 2009).

Phenolic compounds can also have a stimulatory effect on LAB. Free anthocyanins and other phenolic compounds like gallic acid, are able to stimulate cell growth and malic acid degradation of LAB. Phenol carboxylic acids and catechin seem to stimulate the growth of $O$. oeni by enhancing the metabolism of citric acid and reducing the initial lag phase of LAB (Vivas et al., 1997; Rozès et al., 2003). Reguant et al. (2000) saw the stimulation of $O$. oeni growth in the presence of catechin and quercitin. Rozès et al. (2003) studied the effect of phenolic compounds (the phenolic acids $\rho$-coumaric acid, ferulic, cafeic and gallic acid as well as catechin and the anthocyanin malvidin-3-diglucoside) in a synthetic medium on the growth of $O$. oeni. A concentration of 50 $\mathrm{mg} / \mathrm{L}$ of phenolic compounds was stimulatory to $O$. oeni growth. This stimulatory effect could be attributed to the role that phenolic compounds play in protecting bacterial cells from ethanol as well as the fact that phenolic compounds reduce the redox potential of the wine which promotes cell growth (Rozès et al., 2003).

The presence of phenolic compounds also has the potential to influence certain quality parameters in wine. Cavin et al. (1993) reported the ability of $\mathrm{LAB}$ to metabolise hydroxycinnamic acids which result in the formation of volatile phenols with the potential to produce off-flavours. A strain of $O$. oeni studied by Campos et al. (2009), was able to produce higher concentrations of acetate in the presence of phenolic acids. This could be due to enhanced citric acid metabolism at the expense of sugar consumption as documented by Rozès et al. (2003). It was also found that this phenomenon is strain dependant. In contrast, Reguant et al. (2000) found that gallic acid was able to delay or totally inhibit the formation of acetic acid from citric acid. Tannase activity has also been found in L. plantarum strains (not in O. oeni). Tannase activity allows the hydrolysis of ester bonds in hydrolysable tannins. This reaction releases gallic acid and glucose. Tannase activity could potentially play a role in reducing astringency and haze formation in wine (Vaquero et al., 2004).

The effect that phenolic compounds have on LAB metabolic activity and growth, seem to be dependent on the type of compound and its concentration, as well as the strain of LAB.

\section{Lysozyme}

Lysozyme is an enzyme obtained from hen egg white which has been proposed as an alternative to $\mathrm{SO}_{2}$ for the control of LAB and to delay MLF. This enzyme is highly effective against Grampositive bacteria (McKenzie \& White, 1991; Gerbaux et al., 
1997; Bartowsky, 2003; Bartowsky et al., 2004). The enzyme acts by splitting the $\beta$-(1-4) linkage between $\mathrm{N}$-acetyl muramic and $\mathrm{N}$-acetyl-glucosamine, components of the peptidoglycan in the bacterial cell wall, leading to cell lysis and death (McKenzie \& White, 1991; Bartowsky et al., 2004). Both the susceptibility of LAB, as well as the dosage of lysozyme, is important in determining the efficiency of lysozyme in inhibiting LAB and MLF (Bartowsky, 2003).

Not many studies have been done regarding lysozyme and wine. In a model wine, Green \& Daeschel (1994) found ethanol to repress lysozyme activity as well as noting the formation of complexes between lysozyme and phenolics, similar to the lysozyme-phenolic precipitate observed by Bartowsky et al. (2004). Gerbaux et al. (1997) evaluated the ability of lysozyme to reduce the LAB population in wine after the completion of MLF. An addition of $500 \mathrm{mg} / \mathrm{L}$ lysozyme inhibited MLF and an addition of $250 \mathrm{mg} / \mathrm{L}$ promoted microbial stability in red wines after MLF was complete. An added observation of oenological importance was the lack of an increase in acetic acid concentrations in wines that were treated with lysozyme, which were confirmed in results obtained by Gao et al. (2002). Goa et al. (2002) investigated the use of lysozyme in inhibiting spoilage LAB (Lactobacillus kunkeei, L. brevis, $P$. parvulus and $P$. damnosus) in Chardonnay. Besides having no inhibitory effect on yeast growth or sugar metabolism, lysozyme was extremely effective in inhibiting the growth of all the LAB cultures.

In a study by Bartowsky et al. (2004), lysozyme stability as well as the sensorial impact of lysozyme in bottled wines of Riesling, Cabernet Sauvignon and Shiraz were investigated. A fine red coloured pigment was observed in the Cabernet and Shiraz, likely due to the formation of complexes between lysozyme and coloured phenolic pigments. While no precipitate was observed in the Riesling, the lysozyme did cause heat instability or haze formation in the white wine. There were no detectable lysozyme activity in the red wines after two days, attributed to the complex formation and precipitation, while up to $82 \%$ residual activity remained in the Riesling after six months. Despite the fact that a colour difference could be observed due to the pigment precipitation, the sensory panel could not distinguish between the lysozyme treated and untreated wines based on wine aroma and flavour.

The use of lysozyme is an alternative option to $\mathrm{SO}_{2}$ for the control and inhibition of the indigenous LAB population. Lysozyme, in countries where the addition has been legalised, can be utilised as an added tool during the winemaking process to ensure microbial stability with regards to the presence of LAB. An added benefit is the lack of sensory changes associated with the use of lysozyme.

\section{IMPACT OF MALOLACTIC FERMENTATION ON WINE AROMA}

Various studies have shown that MLF has the potential to alter the aroma profile of a wine by the modification or production of flavour-active compounds as depicted in Fig. 1 (Davis et al., 1985; Lonvaud-Funel, 1999; Maicas et al., 1999; Nielsen \& Richelieu, 1999; Gámbaro et al., 2001; Bartowsky et al., 2002b; Bartowsky \& Henschke, 2004; D’Incecco et al., 2004; Swiegers et al., 2005).

Jeromel et al. (2008) found MLF wines to be preferred compared to non-MLF wines and as being more round and full in taste. This is in agreement with findings by Herjavec et al. (2001), that wines in which MLF was suppressed, were inferior compared to wines that were subjected to inoculated or spontaneous MLF. In contrast to these studies, Sauvageot \& Vivier (1997) found that MLF had a minimal, though significant, effect on the aroma of Pinot noir and Chardonnay wines. A possible reason could be that the sensory evaluation of the wines in this study took place two to three years after bottling. This extensive bottling ageing period could have resulted in the modification of the wine aroma profile.

Bartowsky et al. (2002b) compiled a list of descriptors used in the sensory analysis of wines that had undergone MLF. Compared to the control wine that had not undergone MLF, all the wines were readily distinguishable based on these descriptors, which included buttery, nutty, vanilla, fruity, vegetative, toasty and wet leather amongst others. The general consensus was that MLF resulted in a creamier palate, less fruit intensity and more butteriness. In contrast, Henick-Kling (1993) found that MLF enhanced the fruity notes, as well as the buttery aroma, and reduced the vegetative, green and grassy aromas, possibly due to the catabolism of aldehydes (Liu, 2002).

Bartowsky \& Henschke (1995) proposed three mechanisms by which LAB are able to modify wine aroma and flavour: firstly, the bacteria are able to produce volatile compounds by metabolising grape constituents e.g. sugars and nitrogen containing compounds like amino acids; secondly, the modification of grape or yeast derived secondary metabolites by the bacteria and thirdly, adsorption to the cell wall or metabolism of flavour compounds.

There are various important factors to consider when investigating the effect that MLF and LAB have on wine aroma. The changes in aroma and flavour profiles during MLF are also dependant on the bacteria strain responsible for MLF (Bartowsky \& Henschke, 1995; Costello, 2006), as well as on the grape cultivar and winemaking practices (Bartowsky et al., 2002b). One of the most important factors is the matrix effect, where the perception of wine aroma compounds will be significantly altered and effected by the chemical surroundings (Bartowsky et al., 2002b). This implies that an odour-impact compound is not necessarily defined by the concentration at which it occurs in the wine, but rather its threshold value and the contribution that the specific compound makes to the aroma perception of the wine. Other important factors include bacteria-yeast interactions, which also link to the timing of inoculation, precursor availability and enzymatic activity of the malolactic bacteria, as well as whether MLF is completed in a barrel and/or tank.

This section will focus on the main aroma compounds associated with MLF that contribute to the general aroma profile of the wine, as well as some of the key factors that influence their formation. The groups of compounds that will be discussed include carbonyl compounds, esters, sulphur- and nitrogen containing compounds, volatile phenols and volatile fatty acids. A number of these compounds are considered more important due to their larger contribution to the sensory profile and will be discussed in more detail.

\section{Carbonyl compounds}

Diacetyl (2,3-butanedione) is a diketone that contributes buttery, nutty and butterscotch characters to the wine, as well as a yeasty character to sparkling wines, during MLF (Bartowsky \& 
Henschke, 1995; Martineau et al., 1995; Bartowsky et al., 2002b; Bartowsky \& Henschke, 2004). It is considered one of the most important aroma compounds produced during MLF (Bartowsky \& Henschke, 1995; Lonvaud-Funel, 1999). Diacetyl is formed as an intermediate during the metabolism of citric acid by the LAB present during MLF (Fig. 2) (Bartowsky et al., 2002b; Bartowsky \& Henschke, 2004). During carbohydrate metabolism by LAB, pyruvate is reduced to lactate to maintain the redox balance of the bacterial cell. When additional pyruvate is produced as a result of the citric acid metabolism in the absence of sugar, pyruvate is redirected to the production of acetoin and butanediol. Pyruvic acid is reductively decarboxylated to diacetyl via $\alpha$-acetolactate (Lonvaud-Funel, 1999; Bartowsky et al., 2002b; Bartowsky \& Henschke, 2004; Costello, 2006). Due to the fact that diacetyl is chemically unstable, it is further reduced to acetoin, which in turn can be reduced to 2,3-butanediol (Bartowsky et al., 2002b; Costello, 2006).

The accumulation of diacetyl and acetoin is dependent on the rate of MLF. Lower levels of diacetyl and acetoin are produced by a higher MLF rate. Maicas et al. (1999) found decreased levels of diacetyl after MLF, but increased levels of 2,3-butanediol due to the enzymatic reduction of diacetyl by LAB. This conversion has a direct effect on wine aroma, due to the fact that acetoin and 2,3-butanediol have higher threshold values, approximately $150 \mathrm{mg} / \mathrm{L}$ (Francis \& Newton, 2005) and $600 \mathrm{mg} / \mathrm{L}$ (Bartowsky $\&$ Henschke, 2004), respectively, and are therefore considered to contribute to the buttery aroma to a lesser extent (Bartowsky et al., 2002b). In contrast, diacetyl has an odour threshold of approximately $0.2 \mathrm{mg} / \mathrm{L}$ in Chardonnay, $0.9 \mathrm{mg} / \mathrm{L}$ in Pinot noir and $2.8 \mathrm{mg} / \mathrm{L}$ in Cabernet Sauvignon (Martineau et al., 1995). Francis \& Newton (2005) reported diacetyl levels of 0.2 to $1.84 \mathrm{mg} / \mathrm{L}$ generally found in young red wines and 1.25 to $3.39 \mathrm{mg} / \mathrm{L}$ in aged red wines. When concentrations exceed 5-7 $\mathrm{mg} / \mathrm{L}$, the buttery attribute is overpowering and this character is seen as undesirable, whereas concentrations between 1-4 mg/L can contribute to the buttery and butterscotch aroma and add to the complexity of the wine (Bartowsky \& Henschke, 1995, 2004; Swiegers et al., 2005). The sensory perception of diacetyl is highly dependent on a number of factors, including the style, age and type of wine (Swiegers et al., 2005; Costello, 2006), as well as the presence of other compounds that are able to react with diacetyl e.g. $\mathrm{SO}_{2}$ (Martineau et al., 1995; Bartowsky et al., 2002a; Bartowsky \& Henschke, 2004; Swiegers et al., 2005). Table 4 lists the various ways to manipulate the diacetyl content during the winemaking process.

The factors that influence the diacetyl concentration provide a tool for manipulating the final diacetyl concentration in the wine, as well as the impact it has on the final wine aroma (Bartowsky et al., 2002b). Citric acid metabolism only commences towards the end of MLF during sequential AF/MLF when most of the malic acid has been converted to lactic acid. This implies that the maximum concentration of diacetyl will occur at the point where the malic acid is depleted (Bartowsky \& Henschke, 1995, 2004; Nielsen \& Richelieu, 1999). Nielsen \& Richelieu (1999) reported on the relationship between diacetyl and $\mathrm{SO}_{2}$ concentrations in wine during and after MLF. The reaction between $\mathrm{SO}_{2}$ and diacetyl is exothermic and reversible. With the initial addition of $\mathrm{SO}_{2}$ upon completion of MLF, the $\mathrm{SO}_{2}$ binds to diacetyl with a concomitant decrease in the diacetyl concentration. During storage, the reaction is reversed with the resulting increase in diacetyl levels.

By choosing a bacteria strain that possess the ability to produce higher levels of diacetyl, in conjunction with manipulating the temperature, $\mathrm{SO}_{2}$ content and lees contact during the vinification process, a winemaker can manipulate the diacetyl content according to the style of wine required. Some of these factors have a symbiotic effect. A lower $\mathrm{pH}$ will result in more $\mathrm{SO}_{2}$ present in the active antimicrobial form, which will inhibit yeast and bacteria activity and stabilise the diacetyl content. Air contact during MLF will result in a higher wine redox potential which will facilitate the formation of diacetyl from its precursor. The reaction catalysed by pyruvate decarboxylase, responsible for the decarboxylation of pyruvic acid, requires oxygen. Air exposure during MLF will therefore directly influence the metabolic pathway.

\section{Esters}

Esters are important in determining wine aroma and are associated with fruity aromas in wine. The two main groups of fermentationderived esters that have been associated with wine fruitiness are acetate esters and ethyl fatty acid esters. Ethyl fatty acid esters are formed by the enzymatic esterification of activated fatty acids formed during lipid biosynthesis. Acetate esters are formed through the condensation of higher alcohols with acetyl-CoA (Matthews et al., 2004; Ugliano \& Henschke, 2008). Even though the esterase activity of LAB are still being evaluated, it is clear that MLF and wine LAB have the ability to alter the ester content (Matthews et al., 2004). The extent of this alteration is still unclear, with both increases and decreases in ester concentrations being observed in the literature. Malolactic fermentation is generally associated with increased concentrations of ethyl esters, including ethyl lactate, ethyl acetate, ethyl hexanoate and ethyl octanoate (De Revel et al., 1999; Delaquis et al., 2000; Liu, 2002; Swiegers et al., 2005; Jeromel et al., 2008), as well as diethyl succinate. The modulation of aromatic esters by microbial populations has recently been reviewed by Sumby et al. (2009). Table 5 contains some of the esters, other than ethyl lactate and diethyl succinate, associated with MLF and possible aromas that they can contribute to wine.

The most important esters that typically play a role in MLF, are ethyl lactate and diethyl succinate (Maicas et al., 1999; Herjavec et al., 2001; Ugliano \& Moio, 2005). Ethyl lactate is the esterification product of lactate produced by LAB during MLF and ethanol present as a result of AF. This compound is beneficial to the aroma profile due to its fruity, buttery and creamy aromas as well as its contribution to the mouthfeel of the wine (Ugliano \& Moio, 2005). Lloret et al. (2002) determined the aroma threshold of $(S)$-ethyl lactate in wine as $110 \mathrm{mg} / \mathrm{L}$. Wines that had not been subjected to MLF had levels of 5 to $8 \mathrm{mg} / \mathrm{L}$, compared to 90 to $150 \mathrm{mg} / \mathrm{L}$ in MLF wines. Succinic acid is formed as a by-product of microbial $\alpha$-ketoglutarate metabolism, which in turn is slowly and non-enzymatically esterified to form diethyl succinate (Ugliano \& Moio, 2005). This ester also contributes fruity and melon aromas to the wine and has an odour threshold of $1.2 \mathrm{mg} / \mathrm{L}$ (Peinado et al., 2004). Herjavec et al. (2001) found a significant increase in diethyl succinate and ethyl lactate after MLF in Riesling wines, accompanied by a decrease in isoamyl acetate, isobutyl acetate, ethyl butyrate and ethyl caproate. Similarly, Ugliano \& Moio 
TABLE 4

Factors which influence the diacetyl content of wine (Martineau et al., 1995; Bartowsky et al., 2002b; Bartowsky \& Henschke, 2004; Saguir et al., 2009).

\begin{tabular}{|c|c|}
\hline Influencing Factors & Effect on diacetyl concentration and/or sensory perception \\
\hline LAB strain & LAB strains vary in their diacetyl production potential \\
\hline Wine type & Red wine favours diacetyl production compared to white wine \\
\hline Inoculation rate of MLF bacteria & Lower inoculation rate $\left(10^{4}-10^{5} \mathrm{cfu} / \mathrm{mL}\right)$ favours diacetyl production \\
\hline Contact with actual yeast culture and lees & Yeast contact reduces diacetyl content of wine \\
\hline Contact of wine with air during MLF & Oxygen favours oxidation of $\alpha$-acetolactate to diacetyl \\
\hline $\mathrm{SO}_{2}$ content & $\begin{array}{l}\mathrm{SO}_{2} \text { binds diacetyl which renders it sensory inactive } \\
\mathrm{SO}_{2} \text { addition inhibits yeast/LAB activity and stabilises diacetyl content at time of addition }\end{array}$ \\
\hline Citric acid concentration & Favours diacetyl production, however acetic acid is also produced \\
\hline Temperature at which MLF is conducted & $18^{\circ} \mathrm{C}$ vs. $25^{\circ} \mathrm{C}$ may favour diacetyl production \\
\hline Wine $\mathrm{pH}$ at which MLF is conducted & Lower $\mathrm{pH}$ may favour diacetyl production \\
\hline Fermentable sugar concentration & Conflicting information; residual sugar may reduce diacetyl production \\
\hline Wine stabilisation & Immediate stabilisation after malic and citric acid metabolism will increase diacetyl content \\
\hline
\end{tabular}

\section{TABLE 5}

Concentrations, aroma descriptors and thresholds of some of the other esters found in wine that contribute to the aroma during MLF (compiled from Peinado et al., 2004; Francis \& Newton, 2005; Vilanova \& Martínez, 2007).

\begin{tabular}{|c|c|c|c|c|}
\hline \multirow{2}{*}{$\begin{array}{l}\text { Ester } \\
\text { Ethyl hexanoate }\end{array}$} & \multirow{2}{*}{$\begin{array}{l}\text { Aroma descriptor } \\
\text { Apple, fruit, banana, brandy }\end{array}$} & \multicolumn{2}{|c|}{$\begin{array}{l}\text { Concentration }(\mu \mathrm{g} / \mathrm{L}) \text { in } \\
\text { Young red wine Aged red wine }\end{array}$} & \multirow{2}{*}{$\begin{array}{c}\begin{array}{c}\text { Odour Threshold } \\
(\mu \mathrm{g} / \mathrm{L})\end{array} \\
5-14\end{array}$} \\
\hline & & $153-622$ & $255-2556$ & \\
\hline Ethyl octanoate & Fruit, sweet, floral, banana, pear & $138-783$ & $162-519$ & $2-5$ \\
\hline Ethyl butyrate & Apple, fruit, pear, banana & $69.2-371$ & $20-1118$ & 20 \\
\hline Isoamyl acetate & Banana, fruity, sweet & $118-4300$ & $249-3300$ & 30 \\
\hline Phenylethyl acetate & Rose, honey, tobacco, flowery & $0.54-800$ & - & 250 \\
\hline
\end{tabular}

- not reported above threshold in any study.

(2005) found significant increases in ethyl lactate and diethyl succinate.

Maicas et al. (1999) found increases and decreases in the ester concentration as a result of bacterial strain selection. They reported increases in isoamyl acetate, ethyl caproate and 2-phenylethyl acetate. Similarly, Gámbaro et al. (2001) found that ethyl- and acetate ester levels decreased during MLF, but these changes were also dependant on the strain of bacteria used. This coincided with a significant decrease in sensory descriptors like 'berry fruit' and 'fresh vegetative'. Jeromel et al. (2008) also saw a decrease in isoamyl acetate and 2-phenylethyl acetate due to MLF. Delaquis et al. (2000) found an increase in the concentration of ethyl acetate and 3-methyl-1-butyl, which was influenced by the choice of LAB culture. In contrast, ethyl 2-hydroxypropanoate was not influenced by the choice of LAB culture. Ugliano \& Moio (2005) studied the effect of four different malolactic starter cultures of $O$. oeni on the concentration of yeast-derived volatile compounds. Malolactic fermentation increased levels of $\mathrm{C}_{4}-\mathrm{C}_{8}$ ethyl fatty acid esters and 3-methylbutyl acetate, depending on the bacteria strain used. The total increase in ethyl fatty acid esters were generally larger than the increase observed for acetate esters.

Generally, a bacteria strain that exhibits esterase activity contributes to the overall fruitiness of wine and thus the changes in aroma associated with the production and hydrolysis of esters, are dependent on the selected bacteria strain. The majority of O. oeni and Lactobacillus strains evaluated by Davis et al. (1988) showed esterase activity and similarly, all of the strains screened by Matthews et al. (2006) could hydrolyse esters. The most activity was noticed in $O$. oeni strains, followed by Lactobacillus and Pediococcus strains, respectively. Matthews et al. (2007) found that esterase showed greater activity towards short-chained esters $\left(C_{2}\right.$ to $\left.C_{8}\right)$ in comparison to long chained esters $\left(C_{10}\right.$ to $\mathrm{C}_{18}$ ) and significant activity levels still remained under winelike conditions. These results highlight the fact that esterases originating from $\mathrm{LAB}$ could contribute to the wine aroma, if the enzymes are produced and active under wine conditions. 


\section{Glycosides}

Many volatile aroma compounds are present in the grape bound to a sugar moiety (D'Incecco et al., 2004). These compounds are non-volatile in this glycosidic form and represent a reservoir of potential aroma compounds that could make a contribution to the overall perception of wine aroma, if they are released (Bartowsky et al., 2004; D'Incecco et al., 2004; Swiegers et al., 2005). These potential volatiles and sensory important compounds include monoterpenes, $\mathrm{C}_{13}$-norisoprenoids, benzene derivatives and aliphatic compounds (Sefton et al., 1993; D'Incecco et al., 2004; Matthews et al., 2004). Lactic acid bacteria, primarily O. oeni, demonstrate glycosidic activity with the ability to release these volatile compounds so they become odour-active (Grimaldi et al., 2000; Boido et al., 2002; Liu, 2002; Barbagallo et al., 2004; D'Incecco et al., 2004; Matthews et al., 2004). Recently, it has been demonstrated that Lactobacillus and Pediococcus species also possess glycosidase activity (Grimaldi et al., 2005a; Spano et al., 2005). Oenococcus oeni and Lactobacillus strains studied by Hernandez-Orte et al. (2009) were able to release terpenes, norisoprenoids, phenols and vanillins from glycosidic precursors in a model wine solution. The small increments in the concentrations of these compounds caused a broad change in the aroma profile of the samples.

McMahon et al. (1999) found no glycosidase activity in commercial $O$. oeni cultures, whereas Mansfield et al. (2002) saw $\beta$-glucosidase activity in a model system, but none of the strains were active on Viognier grape glycosides. This could imply that the cultivar has an influence on the enzyme activity. In contrast, Grimaldi et al. (2000), Ugliano et al. (2003) as well as Ugliano $\&$ Moio (2006) found a decrease in the concentration of total glycosides and an increase in the free compounds after MLF with $O$. oeni. Boido et al. (2000) found that due to the $\beta$-glucosidase activity of $O$. oeni, the free aroma compounds released from their glycosylated forms increased. They postulated that the increase was smaller than expected due to stable associations between released aroma compounds and bacterial polysaccharides. This could be a possible cause as to why D'Incecco et al. (2004) observed limited liberation of aroma compounds in Chardonnay glycosidic extract during MLF. The degree to which the enzymatic hydrolysis takes place is dependent on the bacterial strain, chemical structure of the substrate and growth phase of the bacteria. Glycosidase activity is also influenced by $\mathrm{pH}$, temperature, sugars and ethanol (Grimaldi et al., 2000, 2005b). The acidic conditions found in wine may denature or inhibit the enzymatic activity. However, O. oeni retained up to $80 \%$ of $\beta$-glucosidase activity at $\mathrm{pH} 3.5$ (Grimaldi et al., 2000). Barbagallo et al. (2004) also showed the ability of wild $O$. oeni strains to retain their $\beta$-glucosidase activity under wine conditions. Mtshali et al. (2010) screened and characterised the $\beta$-glucosidase enzyme in LAB isolated from South African wines. The enzyme specific primers amplified the gene with a size corresponding to $1392 \mathrm{bp}$, with $40 \%$ of the isolates testing positive for the presence of the gene, none of which were $O$. oeni strains. This supports the investigation of alternative LAB genera for possible use in a starter culture that could assist in the liberation of grape-derived aroma compounds.

It is important to further investigate the effect that various stress factors like ethanol and $\mathrm{SO}_{2}$ could have on enzymatic activity and to choose starter cultures that can make a positive contribution to MLF aroma.

\section{Volatile sulphur compounds}

Sulphur containing compounds associated with MLF as a result of LAB metabolism, have not been investigated until as recently as 2004. Pripis-Nicolau et al. (2004) were the first to demonstrate the ability of wine $\mathrm{LAB}$ to metabolise methionine to produce volatile sulphur compounds during MLF. The formation of volatile sulphur compounds in fermented foods has recently been reviewed by Landaud et al. (2008), including volatile sulphur compounds associated with wine. The precise mechanism and biochemical pathways that make up the sulphur metabolism in wine LAB have not been fully investigated and little is known. Figure 3 displays the sulphur metabolism in LAB and it is assumed that wine LAB will share some of the characteristics and pathways characterised in other LAB, specifically LAB from the dairy industry (Liu et al., 2008).

Vallet et al. (2008) proposed the possible pathway by which these compounds are formed by $O$. oeni. The metabolism of methionine by LAB leads to the formation of methanethiol, dimethyl disulphide, 3-(methylsulphanyl)propan-1-ol (also known as methionol) and 3-(methylsulphanyl)propionic acid. The formation of these compounds plays an important role in the complexity of wine aroma because of their characteristic and powerful odours shown in Table 6. Increased concentrations of these sulphur compounds will impart negative aromas to the wine, but concentrations below or close to the odour threshold will add to complexity. The threshold values of some of the most important sulphur compounds are listed in Table 6. Concentrations of methanethiol and 3-(methylsulphanyl)propan1-ol above their thresholds are usually associated with reduction

\section{TABLE 6}

The four main volatile sulphur compounds produced by LAB during MLF and their possible contribution to the wine aroma (Landaud et al., 2008).

\begin{tabular}{|c|c|c|c|c|}
\hline Compound & Aroma descriptor & $\begin{array}{l}\text { Odour threshold } \\
\text { in wine (ppb) }\end{array}$ & $\begin{array}{l}\text { Probable } \\
\text { precursor }\end{array}$ & $\begin{array}{c}\text { Concentration in wine } \\
\text { (ppb) }\end{array}$ \\
\hline Methanethiol & Cooked cabbage, onion & 0.3 & Methionine & $2.1-5.1$ \\
\hline Dimethyl disulfide & Cooked cabbage, ntense onion & $15-29$ & Methanethiol & 2 \\
\hline 3-(methylsulphanyl)propan-1-ol & Cauliflower, cabbage & 500 & Methionine & $140-5000$ \\
\hline 3-(methylsulphanyl)propionic acid & Chocolate, roasted & 244 & Methionine & $0-1811$ \\
\hline
\end{tabular}




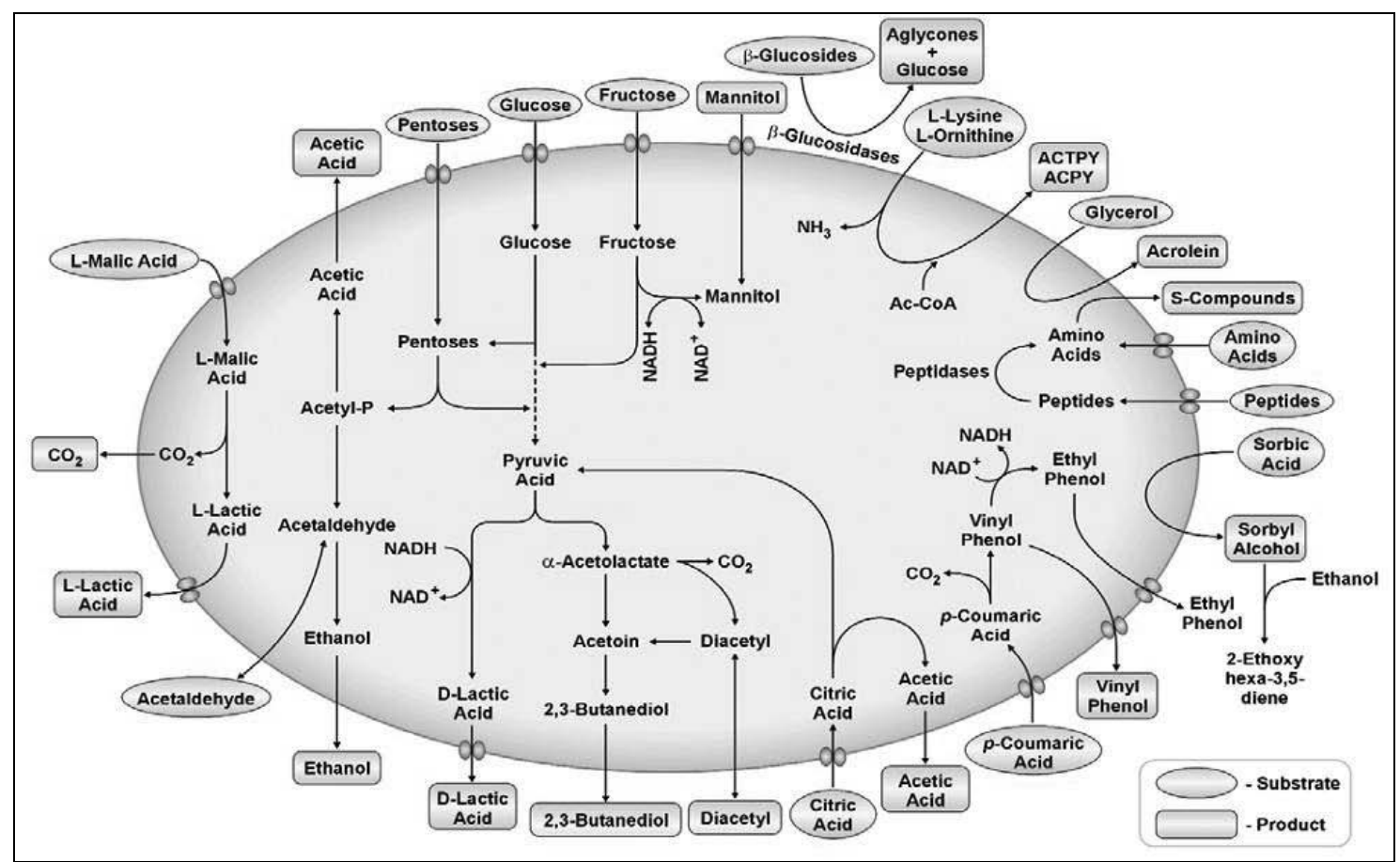

FIGURE 1

A schematic representation of the production and modification of flavour-active compounds by LAB (Swiegers et al., 2005).

off-flavours (Pripis-Nicolau et al., 2004). The production of these volatile sulphur compounds are strain dependant as well as genus dependant, with $O$. oeni having a higher capacity for producing these compounds, compared to the species of Lactobacillus (Pripis-Nicolau et al., 2004).

There are various factors that influence the production of these volatile sulphur compounds, including the presence of methionine as precursor and the growth phase of the bacteria. Vallet et al. (2008) found the production of methionol occurred during the exponential growth phase of the LAB, while the production of 3-(methylthio)propionic acid took place during both the exponential and stationary growth phase. These authors also found that methionol and 3-(methylthio)propionic acid production only occur in the presence of methional, which implies that this compound is an important precursor in their production.

Methional and 2-oxo-4-(methylthiol) butyric acid (KMBA) are the intermediate compounds that are integral in the production of volatile sulphur compounds by $O$. oeni. Methional is converted to methionol and 3-(methylthiol)propionic acid, and can also be produced from the oxidative decarboxylation of KMBA. KMBA also serves as a precursor for the formation of methanethiol and dimethyl disulphide (Vallet et al., 2008). Pripis-Nicolau et al. (2004) found that LAB were able to form all four products in laboratory media, but only 3-(methylsulphanyl)propionic acid levels increased significantly in Merlot red wines. The influence and presence of other compounds in wine have a significant effect on the perceived aroma of 3-(methylsulphanyl)propionic acid. In a synthetic solution, the perception threshold of 3-(methylsulphanyl) propionic acid is $50 \mu \mathrm{g} / \mathrm{L}$ and denotes chocolate and roasted aromas. In contrast, the perception threshold in wine is almost five times higher, $244 \mu \mathrm{g} / \mathrm{L}$, and is associated with 'earthy' and 'red fruit' sensory descriptors.
Besides the four volatile sulphur compounds discussed here, there are also other sulphur containing compounds which potentially alter wine aroma. It is possible for reactions to take place between the sulphur-containing cysteine and $\alpha$-dicarbonyl compounds like diacetyl. These are non-enzymatic reactions that usually take place after MLF and produce tetramethylpyrazine and trimethyloxazole that is associated with 'toasted', 'sulphur' and 'cabbage' aromas (Pripis-Nicolau et al., 2000; Swiegers et al., 2005; Landaud et al., 2008).

\section{Nitrogen containing compounds}

Wine LAB are able to produce heterocyclic volatile nitrogen bases responsible for the 'mousy' off-flavours encountered in spoilage wines. Three main compounds are involved: 2-acetyl-1-pyrroline (ACPY), 2-ethyltetrahydropyridine (ETPY) and 2-acetyltetrahydropyridine (ACTPY) (Lonvaud-Funel, 1999; Costello et al., 2001). The formation of these compounds is mostly associated with heterofermentative LAB, such as $O$. oeni, some Lactobacillus species and Leuc. mesenteroides, via the metabolism of certain amino acids, specifically ornithine and lysine (Costello et al., 2001; Swiegers et al., 2005). ACTPY and ACPY are the most powerful odorants compared to ETPY, with thresholds in water of $1.6 \mu \mathrm{g} / \mathrm{L}$ and $0.1 \mu \mathrm{g} / \mathrm{L}$, respectively. Wines that are considered spoiled by the 'mousy' off-flavours generally contain amounts of 2.7 to $18.7 \mu \mathrm{g} / \mathrm{L}$ of ATPY, up to $7.8 \mu \mathrm{g} / \mathrm{L}$ ACPY and 4.8 to $106 \mu \mathrm{g} / \mathrm{L}$ of ACTPY. These compounds are either present in combination or individually. The availability of the precursor's lysine and ornithine has a significant impact on the ability of LAB to produce these compounds (Costello \& Henschke, 2002). Costello \& Henschke (2002) also found that the lack of ethanol drastically reduces the ability of $L$. hilgardii to produce $\mathrm{N}$ heterocycles, whereas elevated concentrations of acetaldehyde stimulates formation. Lactic acid bacteria differ in their preference 


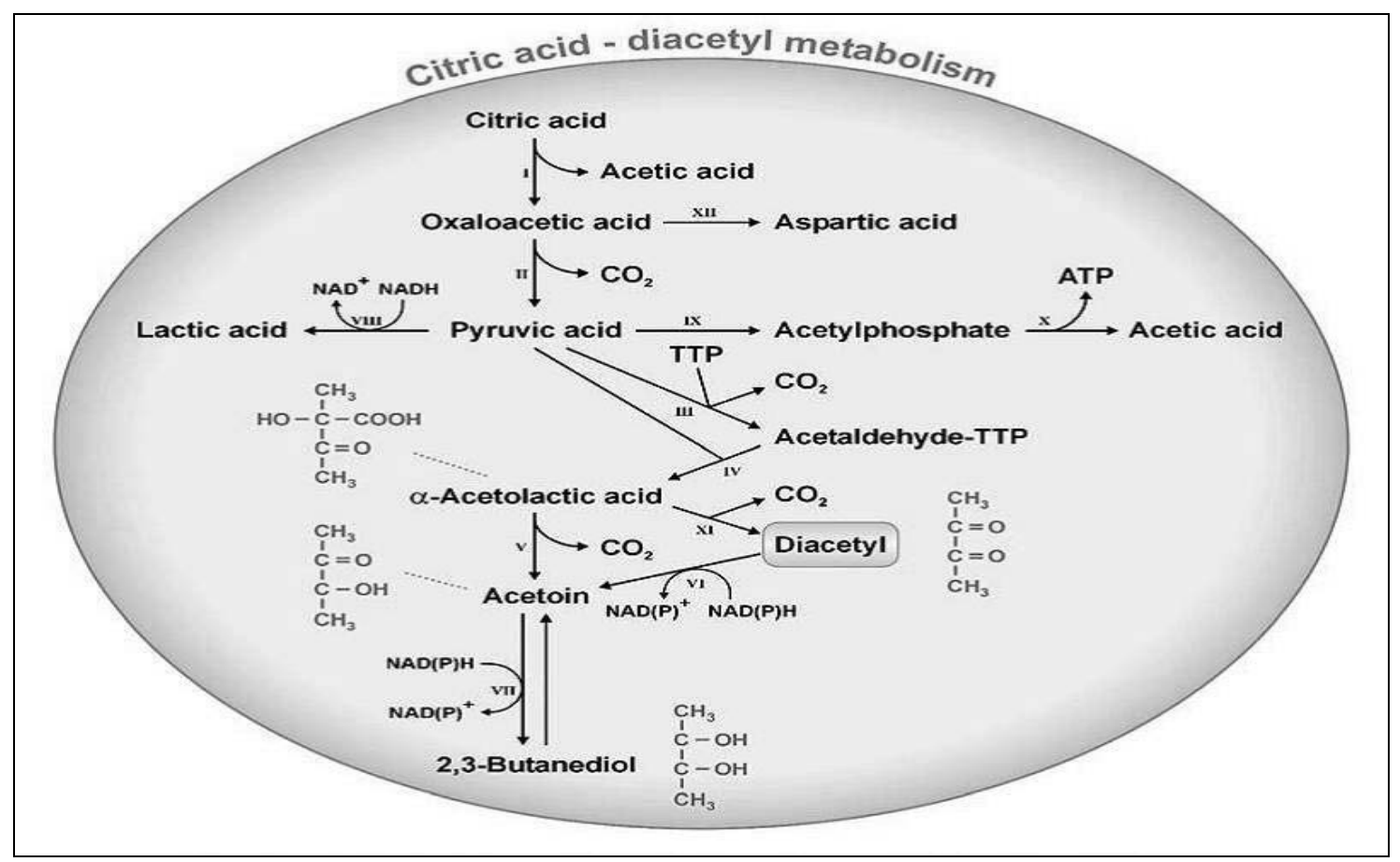

FIGURE 2

A schematic representation of citric acid metabolism and the synthesis of diacetyl in LAB (I: citrate lyase; II: oxaloacetate decarboxylase; III: pyruvate decarboxylase; IV: $\alpha$-acetolactate synthase; V: $\alpha$-acetolactate decarboxylase; VI: diacetyl reductase; VII: acetoin reductase; VIII: lactate dehydrogenase; IX: pyruvate dehydrogenase complex; X: acetate kinase; XI: non-enzymatic decarboxylation; XII: aspartate aminotransferase) (Swiegers et al., 2005).

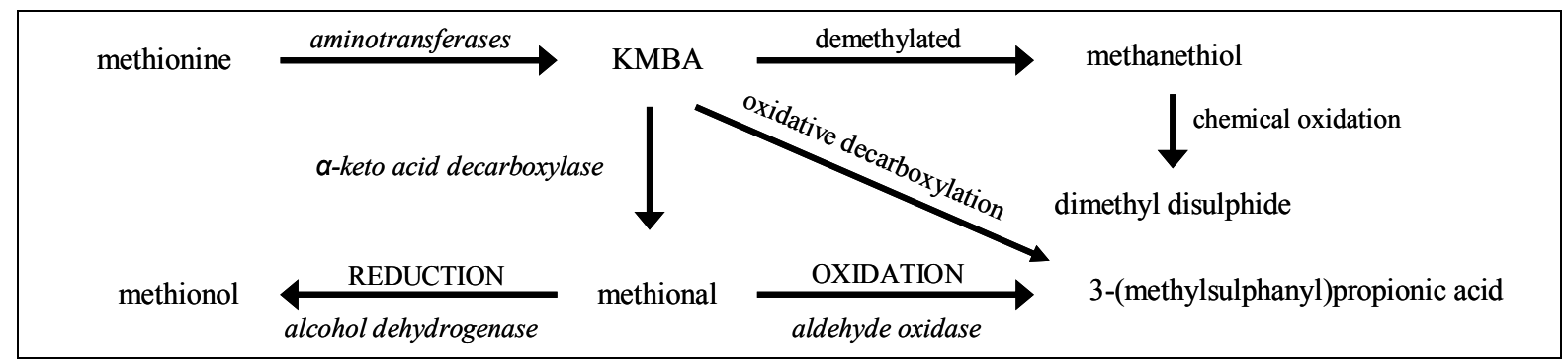

FIGURE 3

The production of the four major volatile sulphur compounds produced by LAB metabolism [Compiled from Landaud et al. (2008) and Vallet et al. (2008)].

for the formation of the different nitrogen heterocyclic compounds. Oenococcus oeni favours the production of the least flavour active ETPY, the heterofermentative lactobacilli the formation of ACTPY and the homofermentative pediococci the formation of the most flavour active ACPY. In general, the heterofermentative LAB show the highest ability to produce nitrogen-heterocycles and mousy off-flavours (Swiegers et al., 2005).

\section{Volatile phenols}

Wine contain various phenolic compounds, of which the phenolic acids, specifically $\rho$-coumaric acid and ferulic acid, can be utilised as substrates by wine LAB in the formation of volatile phenol aroma compounds (Cavin et al., 1993; Lonvaud-Funel, 1999). The bacteria are able to make use of an active transport mechanism to transfer the phenolic acids into the cell, where hydroxycinnamic acid decarboxylases are able to decarboxylate the phenolic acids to their vinyl derivatives (4-vinylguaiacol and 4-vinylphenol). In turn, the vinyl derivatives can be enzymatically reduced to the corresponding ethyl derivatives (4-ethylguaiacol and 4-ethylphenol) (Cavin et al., 1993; Swiegers et al., 2005). The vinyl derivatives can impart pharmaceutical odours to the wine (Ribéreau-Gayon et al. 2002) and the products, 4-ethylphenol and 4-ethylguaiacol, give rise to 'animal' and 'medicinal' aromas as well as horse sweat, horse stable, barnyard and elastoplast aromas (Lonvaud-Funel, 1999). These aroma descriptors are generally associated with the presence of the spoilage yeast Brettanomyces (Chatonnet et al., 1992). The ability of LAB to produce volatile phenols supports the theory that these characteristic aromas are not solely produced by Brettanomyces. This theory was supported by results from Nelson (2008). In this study, the influence of different MLF scenarios on the production of volatile phenols was investigated. Lactic acid bacteria used in this study were able to produce significant levels of volatile phenols. It was also found that spontaneous MLF resulted in higher levels of volatile phenols. 
TABLE 7

A summary of routinely used methods for malic acid and MLF monitoring including the advantages and disadvantages of each method [compiled from Kollar \& Brown (2006) and Theodore (2006)].

\begin{tabular}{lll}
\hline Monitoring Technique & Advantages & Disadvantages \\
\hline Paper Chromatography (PC) & & - strictly qualitative so still need quantitative \\
- separate compounds based on their polarity & - easy to use & values to verify MLF completion \\
- visually follow disappearance of malic acid & - simple, affordable and indicative of MLF progress & - not precise \\
- commonly used in winery & & - not specific for L-malic acid
\end{tabular}

Thin Layer Chromatography (TLC)

- similar to PC but uses TLC plates instead of paper

\section{Reflectance}

- Reflectoquant ${ }^{\circledR}$

- based on reflectance photometry

- use reactive test strips to analyze for various wine components
- easy to use
- simple and affordable
- results in one hour; much faster than PC

- a fraction of the cost of a spectrophotometer

- half of the cost of an enzymatic kit

- measure multiple wine parameters

- fastest method currently available ( $5 \mathrm{~min} / \mathrm{sample})$

- relative accuracy of $10 \%$

\author{
- not precise \\ - not specific for L-malic acid; \\ - strictly qualitative so still need quantitative \\ values to verify MLF completion
}

\section{Enzymatic analysis}

- uses enzyme that specifically react with $\mathrm{L}$-malic acid then use UV-visible spectrophotometer to monitor enzymatic reaction

- most commonly used method

- MLF complete if malic acid is less than 200 to $300 \mathrm{mg} / \mathrm{L}$

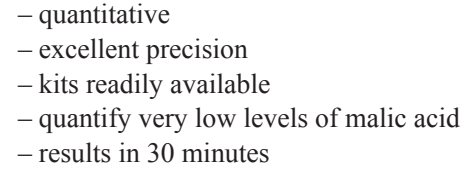

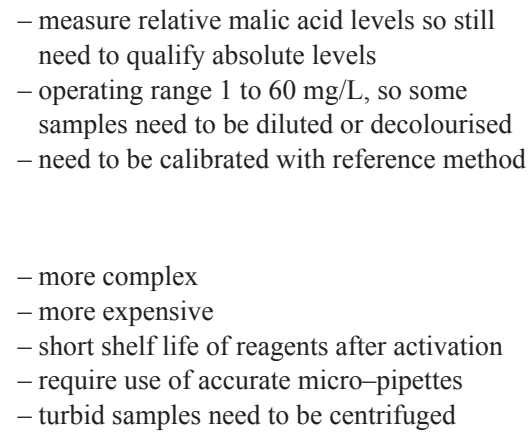

\author{
- more complex \\ - more expensive \\ - short shelf life of reagents after activation \\ - require use of accurate micro-pipettes \\ - turbid samples need to be centrifuged
}

Capillary electrophoresis (CE)

Fourier-Transform Infrared (FT-IR) Spectroscopy

- use infrared spectra to quantify wine parameters

\author{
- highly accurate \\ - short analyses time, fast results
}

High performance liquid chromatography (HPLC) - separation of compounds based on polarity and interaction with stationary or solid phase

\author{
- accurate \\ - small sample volume \\ - short analyses time, fast results
}

\author{
- extremely expensive \\ - not recommended for everyday use in \\ winery
}

- expensive equipment

- accuracy dependant on reference values and calibration curve
Despite the fact that it has been established that LAB contribute to the volatile phenol concentration, it is still unclear if strains of $O$. oeni are able to produce levels of 4-vinylguaiacol and 4-vinylphenol that could be of sensorial significance (Swiegers et al., 2005). This was supported by the findings of Gámbaro et al. (2001), which only saw a small increase in 4-vinylguaiacol and 4-vinylphenol in Tannat wines that underwent MLF. These levels were below the odour threshold.

The fact that $\mathrm{LAB}$ are able to contribute to the volatile phenol concentration in wine, emphasise the need to screen commercial MLF cultures for the potential to produce volatile phenols.

\section{Acetic acid}

Acetic acid is the most important volatile acid produced during fermentation, both quantitatively and sensorially. The flavour threshold for acetic acid is dependent on both the type and style of wine (Bartowsky \& Henschke, 1995; Lonvaud-Funel, 1999; Ugliano \& Henschke, 2008). Acetic acid leads to a sour, pungent and vinegar aroma in wine (Francis \& Newton, 2005) in concentrations exceeding $0.7 \mathrm{~g} / \mathrm{L}$ (Swiegers et al., 2005). Lower concentrations, 0.2 to $0.6 \mathrm{~g} / \mathrm{L}$, can contribute to the complexity of wine aroma. There is an increase in acetic acid of 0.1 to $0.2 \mathrm{~g} / \mathrm{L}$, which is generally associated with MLF (Bartowsky \& Henschke, 1995).

There are two proposed mechanisms by which LAB can increase acetic acid levels in wine. If MLF commences before the completion of AF, the LAB are able to ferment hexoses that have not been completely fermented by the yeast. Oenococcus oeni is a heterofermentative strain and will not only produce ethanol and $\mathrm{CO}_{2}$, but also acetic acid and D-lactic acid, via the 6-PG/ 
TABLE 8

A summary of molecular techniques available for monitoring and characterisation of the microbial population during MLF.

\begin{tabular}{|c|c|c|}
\hline Technique & Application & Reference \\
\hline Polymerase chain reaction (PCR) & $\begin{array}{l}\text { - Specific PCR primers target and amplify either 16S rRNA genes } \\
\text { or genes encoding the MLE } \\
\text { - distinguish LAB genera }\end{array}$ & $\begin{array}{l}\text { Bartowsky et al. (2003) } \\
\text { Zapparoli et al. (1998) }\end{array}$ \\
\hline $\begin{array}{l}\text { Randomly amplified polymorphic DNA } \\
\text { (RAPD) analysis } \\
\text { (a PCR-based technique) }\end{array}$ & $\begin{array}{l}\text { - Quick and sensitive discrimination of LAB strains } \\
\text { - Follow O. oeni population changes during MLF }\end{array}$ & Bartowsky et al. (2003) \\
\hline $\begin{array}{l}\text { PCR-denaturing gradient gel electrophoresis } \\
\text { (PCR-DGGE) }\end{array}$ & $\begin{array}{l}\text { - Identify and distinguish LAB } \\
\text { - Monitor spoilage microorganisms during fermentation }\end{array}$ & $\begin{array}{l}\text { Renouf et al. (2006) } \\
\text { Spano et al. (2007) }\end{array}$ \\
\hline $\begin{array}{l}\text { Real-time PCR and differential real-time } \\
\text { PCR assay }\end{array}$ & $\begin{array}{l}\text { - Rapid detection and quantification of } O \text {. oeni } \\
\text { - Enumerate total LAB population to assess spoilage risk of juice/wine by LAB }\end{array}$ & $\begin{array}{l}\text { Pinzani et al. (2004) } \\
\text { Neeley et al. (2005) }\end{array}$ \\
\hline $\begin{array}{l}\text { Restriction analysis of the amplified 16S- } \\
\text { rDNA (PCR-ARDRA) }\end{array}$ & - Identification of species of LAB & Rodas et al. (2003) \\
\hline $\begin{array}{l}\text { Transverse alternating field lectrophoresis } \\
\text { (TAFE) and Pulsed-field gel lectrophoresis } \\
\text { (PFGE) }\end{array}$ & $\begin{array}{l}\text { - Patterns of digested chromosomal } \\
\text { DNA used to differentiate closely related } O \text {. oeni strains }\end{array}$ & Versari et al. (1999) \\
\hline $\begin{array}{l}\text { Contour-clamped homogenous electric field } \\
\text { (CHEF) (a specific type of PFGE) }\end{array}$ & $\begin{array}{l}\text { - Most reliable for strain differentiation } \\
\text { - Produce unique DNA fingerprint for individual strains }\end{array}$ & Bou \& Powell (2006) \\
\hline
\end{tabular}

PK pathway. As a consequence, the volatile acidity increases slightly (Lonvaud-Funel, 1999; Swiegers et al., 2005). During the formation of diacetyl, LAB can also produce acetic acid during the first reaction of the citric acid metabolic pathway catalysed by the citrate lyase enzyme (Bartowsky et al., 2002b; Bartowsky $\&$ Henschke, 2004). The rate of acetic acid accumulation is dependent on the rate of MLF, with higher concentrations of acetic acid being formed in conjunction with a higher MLF rate (Lonvaud-Funel, 1999). It has been shown by recent studies that the common belief that co-inoculation will lead to higher acetic acid concentrations is not true.

\section{Volatile fatty acids}

Volatile fatty acids are formed by the hydrolysis of tri-, di- and monoacylglycerols (lipids) (Liu, 2002). Wine consists of a mixture of straight chain fatty acids and branched chain fatty acids. The straight chain fatty acids are usually referred to as short chain $\left(\mathrm{C}_{2}-\mathrm{C}_{4}\right)$, medium chain $\left(\mathrm{C}_{6}-\mathrm{C}_{10}\right)$ or long chain $\left(\mathrm{C}_{12}-\mathrm{C}_{18}\right)$ fatty acids (Ugliano \& Henschke, 2008). As the chain length of fatty acids increase, the volatility decreases and the odour changes from sour to rancid and cheesy (Francis \& Newton, 2005; Ugliano \& Henschke, 2008).

Maicas et al. (1999) found no significant increase in isovaleric, isobutyric and hexanoic acids after MLF, although capric acid and caprylic acid levels were higher. This lack of significant increase could be beneficial to wine aroma due to the fact that isobyturic and isovaleric acids are associated with rancid, butter, cheese and sweaty aromas (Francis \& Newton, 2005). Similarly, Herjavec et al. (2001) saw a significant increase in caprylic acid, as well as increased in caproic- and capric acid concentrations. Lipases are able to produce volatile fatty acids but the lipase activity in wine LAB still warrants further investigation (Liu, 2002).

\section{Higher alcohols}

Higher alcohols are formed by the decarboxylation and subsequent reduction of $\alpha$-keto acids. The keto acids are produced as intermediates during amino acid biosynthesis and catabolism, the latter referred to as the Ehrlich pathway. Amino acid biosynthesis is responsible for most of the higher alcohols formed during fermentation (Ugliano \& Henschke, 2008). At lower concentrations (less than $300 \mathrm{mg} / \mathrm{L}$ ), higher alcohols can contribute to the complexity and fruity aromas in wine, whereas higher concentrations (above $400 \mathrm{mg} / \mathrm{L}$ ) could be detrimental to wine aroma and quality due to the harsh chemical-like aromas (Swiegers et al., 2005).

Jeromel et al. (2008) found that MLF had an insignificant effect on the higher alcohol concentration of wine, except for significant increases in isobutanol and 2-phenylethanol. In contrast, Herjavec et al. (2001) found no change in levels of 1-propanol, isobutanol, isoamyl alcohol or 2-phenylethanol. This is supported by Maicas et al. (1999) who found the production of isobutanol, 1-propanol, 1-butanol and isoamyl alcohol to be dependent on the strain used to perform MLF. Pozo-Bayón et al. (2005) saw increased levels of higher alcohols after MLF, but none of the increases were significant. The fact that LAB seem to have limited ability to produce higher alcohols could be beneficial, as most of these compounds impart harsh solvent-like aromas in the wine. The concentration of higher alcohols that have either a positive or 
negative influence on the wine aroma, is likely to depend on both the aroma intensity of the respective alcohols as well as the style of wine (Ugliano \& Henschke, 2008).

Based on the available literature, it is clear that MLF has an effect on the sensory character of wine. These effects are diverse and sometimes contradicting and may be due to the following factors: the influence of the different bacteria strains, the presence and availability of precursors, LAB associated enzymatic activity, the wine type as well as the intensity of the inherent wine flavour and cultivar character, the vinification conditions under which the wine was produced as well as the training and skills of the sensory panel that evaluate the wine.

Malolactic fermentation generally leads to an increase in the buttery attribute, reduced vegetative character, modification in the fruitiness and improved mouthfeel and flavour persistence. Wine aroma is also influenced by the type of LAB and possible wood interactions. Due to the influence that MLF has on the aroma properties of a wine, it is essential for the winemaker to understand the formation of these compounds, the factors that influence their occurrence in wine and the ways in which to manipulate their production. This will enable wine producers to create a specific style of wine in an industry where consumer preference is the driving force for product development.

Future research should include the investigation into the identification and quantification of relevant aroma precursors; the vineyard practices that influence their occurrence and concentration, the effect of assorted vinification processes on the evolution of these precursors to aroma active compounds (Swiegers et al., 2005), as well as the mechanisms of how LAB contribute to this process. The enzymatic profiles of wine LAB warrant further investigation as well as the factors that influence the activity of these enzymes under winemaking conditions. The choice of bacterial strain seems to be one of the most influential factors on the production of odour-impact compounds associated with MLF.

\section{IMPACT OF MALOLACTIC FERMENTATION ON WINE WHOLESOMENESS}

\section{Biogenic amines}

Biogenic amines are a group of organic nitrogen-containing compounds. The main biogenic amines associated with wine are putrescine, histamine, tyramine and cadaverine, followed by phenylethylamine, spermidine, spermine, agmatine and tryptamine (Ten Brink et al., 1990; Lonvaud-Funel, 2001). The role of biogenic amines in wine and the microorganisms involved in their synthesis, were recently reviewed by Smit et al. (2008).

Biogenic amines are formed by certain LAB via the substratespecific enzymatic decarboxylation of naturally occurring amino acids (Ten Brink et al., 1990; Lonvaud-Funel, 2001). These compounds are of importance in wine due to their potential toxicological effects in sensitive humans. These include symptoms like headaches, hypo- or hypertension, cardiac palpitations and in extreme cases even anaphylactic shock (Shalaby, 1996). It is imperative to be able to identify strains with the potential to produce biogenic amines. The ingestion of biogenic amines, histamine in particular, can lead to various health reactions in sensitive humans. Phenylethylamine and tyramine can cause symptoms of high blood pressure and migraines. Putrescine and cadaverine, besides being able to enhance the toxicity of histamine, tyramine and phenylethylamine, can also have a detrimental effect on wine quality by imparting flavours of putrefaction and rotten meat, respectively (Shalaby, 1996; Palacois, 2006). The presence of alcohol, $\mathrm{SO}_{2}$ and other amines could potentially amplify the toxic effect of certain biogenic amines (Fernandes \& Ferreira, 2000; Volschenk et al., 2006). There are various factors that influence the biogenic amine content. These factors include the amino acid composition, the microflora present in the wine and the ability of the microflora to decarboxylate amino acids. All parameters that favour bacterial growth will favour biogenic amine formation (Lonvaud-Funel \& Joyeux, 1994; Volschenk et al., 2006).

The essential role of LAB and MLF in the formation of biogenic amines has been confirmed by various authors (Lonvaud-Funel \& Joyeux, 1994; Moreno-Arribas et al., 2000; Marcobal et al., 2006; Volschenk et al., 2006; Landete et al., 2007a). LonvaudFunel \& Joyeux (1994) reported increased concentrations of biogenic amines after MLF and Landete et al. (2007a) reported histamine, tyramine, phenylethylamine and putrescine production by LAB. Similarly, in a study on the changes in biogenic amine concentration during the industrial manufacturing of red wines, Marcobal et al. (2006) identified MLF as the main mechanism of biogenic amine formation, especially the production of histamine, tyramine and putrescine.

It is generally accepted that spoilage LAB are responsible for the formation of biogenic amines, specifically species of Pediococcus and Lactobacillus (Moreno-Arribas \& Polo, 2008). Landete et al. (2007b) identified L. brevis to be the main producer of tyramine and phenylethylamine. Arena \& Manca de Nadra (2001), as well as Manfroi et al. (2009), highlighted the ability of L. hilgardii to produce putrescine and also found that $L$. plantarum strains have the ability to produce biogenic amines. Recent research also identified $O$. oeni as a possible biogenic amine producer. MorenoArribas et al. (2000) identified $O$. oen $i$ as the main LAB responsible for histamine formation and lactobacilli for tyramine formation. Lucas et al. (2008) identified 54 colonies of histamine producing isolates as $O$. oeni and despite the fact that histamine producing $O$. oeni are frequently found in wine, it was also found that LAB may lose this ability due to instability of the phenotype. Histamine producing LAB all carry an $h d c A$ gene coding for a histidine decarboxylase (HDC) that converts histidine to histamine. This $h d c A$ gene was detected on a large and possibly unstable plasmid, which could result in a loss of histamine producing ability.

In an investigation of the biogenic amine producing capability of several strains of $O$. oeni, more than $60 \%$ were able to produce histamine in concentrations ranging from 1.0 to $33 \mathrm{mg} / \mathrm{L}$. An additional $16 \%$ had the added capability of producing putrescine and cadaverine (Geurrini et al., 2002). Landete et al. (2005a) showed the highest frequency of histamine production by $O$. oeni. In the same study, $O$. oen $i$ was also shown to produce the lowest concentrations of histamine, whereas higher concentrations were produced by Lactobacillus and Pediococcus strains, specifically P. parvulus and L. hilgardii. In contrast, Izquierdo et al. (2009) found that $O$. oeni did not significantly contribute to the overall biogenic amine content in wine. Rosi et al. (2009) studied 26 strains of $O$ oeni for their biogenic amine formation ability in synthetic medium and wine. These authors found that the concentration of histamine and tyramine formed by $O$. oen $i$ were 
dependant on the bacterial strain, the effect of the yeast strain on the wine composition, the length of bacteria-yeast contact time after MLF completion, as well as the screening method used for biogenic amine determination.

There are various oenological parameters that influence the decarboxylase enzyme activity as well as the biogenic amine producing ability of LAB (Landete et al. 2008). Histidine decarboxylase activity is enhanced at $\mathrm{pH} 3.5$ and has an optimum $\mathrm{pH}$ of 4.8 (Lonvaud-Funel \& Joyeux, 1994). Tyrosine decarboxylase (TDC) is active in the $\mathrm{pH}$ range of 3 to 7 , but exhibits optimum activity at pH 5 (Moreno-Arribas \& Lonvaud-Funel, 1999). In wines with higher $\mathrm{pH}$ values, decarboxylase positive bacteria are more likely to survive. This means that in most cases, a higher $\mathrm{pH}$ will concomitantly lead to higher biogenic amine concentrations (Wibowo et al., 1985; Lonvaud-Funel \& Joyeux, 1994; Gardini et al., 2005; Landete et al., 2005b; Martin-Álvarez et al., 2006). At a higher $\mathrm{pH}$, the $\mathrm{SO}_{2}$ fraction will be less effective which can also result in a higher concentration of biogenic amines (Gerbaux \& Monamy, 2000). A higher $\mathrm{SO}_{2}$ concentration will also prevent the formation of biogenic amines by reducing the viable LAB population in wine (Marcobal et al., 2006). Another important factor is the ethanol content of the wine. In general, higher ethanol concentrations lead to a decrease in the formation of biogenic amines (Gardini et al., 2005). It was found that a high ethanol concentration reduces HDC activity by altering the membrane properties of LAB and thereby slowing down histidine transport (Rollan et al., 1995). Lonvaud-Funel \& Joyeux (1994) found that an ethanol level of up to $10 \%(\mathrm{v} / \mathrm{v})$ enhances HDC activity and Mazzoli et al. (2009) saw a decrease in bacterial growth and biogenic amine formation at ethanol concentrations exceeding $13 \%(\mathrm{v} / \mathrm{v})$.

The ability to produce biogenic amines is used as a screening criterion in the selection of LAB starter cultures. Le Jeune et al. (1995) developed a detection system for histamine producing LAB strains and more recently, Marcobal et al. (2005) selected three primer pairs to use in a multiplex-PCR assay to simultaneously detect histamine, tyramine and putrescine producing LAB. The assay yielded a 367 bp DNA fragment from histidine decarboxylases $(h d c)$ (primer pair JV16HC/JV17HC), a 924 bp fragment from tyrosine decarboxylases $(t d c)$ (primer pair P1-rev/ P2-for) and a $1446 \mathrm{bp}$ fragment from ornithine decarboxylases $(o d c)$ (primer pair 3/16). The first PCR detection for cadaverine producing LAB has also been developed (De las Rivas et al., 2006).

In a study investigating the potential of commercial cultures to produce tyramine, histamine and putrescine, it was found that none of the commercial starter cultures produced biogenic amines (Moreno-Arribas et al., 2003). In a study comparing spontaneous and inoculated MLF in Spanish red wine, the incidence of biogenic amines was reduced in the inoculated MLF (Martín-Álvarez et al., 2006). Similarly, Izquierdo et al. (2007) determined that histamine, tyramine and putrescine concentrations increased by $68 \%$ in Spanish wines due to spontaneous MLF.

Inoculation for MLF with a starter culture that does not have the ability to produce biogenic amines will eliminate the risk of biogenic amine formation associated with spontaneous MLF.

\section{Ethylcarbamate}

Ethylcarbamate (EC) is a suspected carcinogen (Fugelsang \&
Edwards, 1997). Lactic acid bacteria, including commercial strains of $O$. oeni, are able to degrade arginine via the arginine deiminase pathway. There are three enzymes that play a role in this pathway. Arginine deiminase is responsible for the production of L-citrulline from L-arginine. Ornithine transcarbamylase then converts L-citrulline to L-ornithine and carbamyl phosphate. The final reaction is catalysed by carbamate kinase during which ATP is generated from carbamyl phosphate. The catabolism of arginine contributes to LAB growth due to the generation of ATP, but two of the intermediates formed, citrulline and carbamyl phosphate, are able to react with ethanol to form EC (Liu et al., 1994, 1995; Arena \& Manca de Nadra, 2002; Volschenk et al., 2006; Araque et al., 2009). Strains of O. oeni and Lactobacillus buchneri are able to excrete citrulline and carbamyl phosphate (Liu et al., 1994; Mira de Orduña et al., 2000, 2001) and Uthurry et al. (2006) also found that strains of $O$. oeni and L. hilgardii were able to contribute to the EC concentration. Recently, Romero et al. (2009) found L. plantarum strains in this study were unable to degrade arginine to form citrulline.

Araque et al. (2009) investigated the presence of genes involved in the deiminase pathway that are responsible for the degradation of arginine in different LAB species. The degrading strains included L. brevis and L. hilgardii, O. oeni, P. pentosaceus, and some strains of Leuc. mesenteroides and, contrary to Romero et al. (2009), also L. plantarum. Uthurry et al. (2006) also found increased concentrations of EC after MLF in Tempranillo and Cabernet Sauvignon wines, irrespective of the bacterial strain or different conditions of $\mathrm{pH}$ and temperature. In contrast, Romero et al. (2009) found the conditions that led to a slight increase in EC formation by $O$. oeni to be high ethanol concentrations, low $\mathrm{pH}$, high L-malic acid concentrations and higher temperatures.

Inhibition of the LAB population immediately after the completion of MLF could avoid the formation of citrulline from arginine and concomitant EC formation (Terrade \& Mira de Orduña, 2006).

\section{MALOLACTIC FERMENTATION MONITORING}

\section{Monitoring of malic acid concentration}

The decrease in malic acid or increase in lactic acid is mostly used to monitor the progression of MLF. There are various useful analytical techniques available for monitoring the malic acid concentration. These methods include chromatography, reflectance and enzymatic assays, as well as analytical techniques like Fourier-transform infrared (FT-IR) spectroscopy and capillary electrophoresis (CE) or the use of high-performance liquid chromatography (HPLC). These techniques differ in their accuracy, time needed for analysis as well as the cost involved. A summary of the monitoring techniques, as well as the advantages and disadvantages, are provided in Table 7.

Chromatography, like paper chromatography (PC) and thin layer chromatography (TLC), is the method most often implemented in wineries due to the low cost involved. Unfortunately, these methods are not as accurate as some of the analytical techniques. The more accurate methods usually involve the acquirement of expensive equipment like a CE or HPLC. In order to accurately monitor the progression of MLF, fast and accurate results are required. The use of an enzymatic kit could address both of these aspects. Although the cost involved is still relatively high, it is 
still less expensive than acquiring instruments like an HPLC or a FT-IR spectrometer. The commercial scale of the cellar and the amount of samples to be analysed on a regular basis, will greatly influence the selection of the most suitable malic acid monitoring technique.

\section{Monitoring of microbial population}

Monitoring of the microbial population is important in identifying the LAB responsible for MLF, possible spoilage LAB as well as determining the viable microbial population. This will provide the winemaker with control over the MLF process, as well as preventing possible problems before they arise. There are two established microbiological techniques that are generally used, including microbial plate counts and microscopy.

Microbial plate counts refer to the isolation of LAB after which the number of viable LAB in the wine is determined. This requires the growth of the bacterial cells on a nutrient medium. An advantage of this method is the fact that spoilage LAB like Pediococcus and Lactobacillus can grow in 2 to 4 days, so results can be quickly obtained. On the other hand, the slow growth of O. oeni, up to 7 days, can mean a delay in obtaining the results. This method also requires appropriate sterile equipment and nutrient media.

Microscopy is an alternative technique for monitoring the microbial population and is based on the direct observation of a wine sample using a microscope. This allows for fast evaluation of the microflora in the wine. It is possible to instantly identify the bacterial population due to the distinct morphologies which allow for discrimination of wine LAB (Kollar \& Brown, 2006). Oenococcus oeni are some of the smallest cells in wine and appear round or slightly elongated and usually form distinct chains of individually linked cells. It is generally accepted that the longer the chains, the 'healthier' the population. If only single cells or pairs of $O$. oeni are visible (except directly after starter culture additions when chains are broken because of the drying process), the culture is usually no longer viable. Pediococcus cells are almost completely round and do not form chains. They appear singly, in pairs, tetrads or small bunches and appear bright white under the microscope. Lactobacillus is rod shaped and appears as single cells or pairs in wine and also appears bright white under the microscope (Dicks \& Endo, 2009). The disadvantage of this technique is the fact that it requires a quality bright field microscope with 1000X magnification capability. This method is also not quantitative without specific tools (Kollar \& Brown, 2006).

There are various molecular techniques available that aid in the characterisation of LAB and add to the knowledge of these bacteria and their role in the winemaking process (Lonvaud-Funel, 1995). These techniques enable us to identify microbes, differentiate LAB from each other as well as distinguish between different strains within the same species (Table 8) (Bartowsky et al., 2003). Some of these techniques include: DNA-DNA hybridisation, 16S and 23S rRNA sequence analysis, DNA-fingerprinting and pulsefield gel electrophoresis (PFGE) as well as PCR-based DNA fingerprinting known as randomly amplified polymorphic DNA (RAPD) analysis (Bartowsky et al., 2003). These techniques are used to identify and differentiate between LAB (Zapparoli et al., 1998; Bartowsky \& Henschke, 1999).
Despite the fact the PFGE analysis is the most reliable technique for strain differentiation, as well as being used in strain selection for new starter cultures, it takes up to 3 days to generate results. Future techniques that require further development and need to be improved, include DNA sequencing, amplified fragment length polymorphism (AFLP), ribotyping as well as species-specific and multiplex-PCR.

\section{CONCLUSIONS}

The information available on MLF and LAB can assist the winemaker in ensuring successful MLF which involves the complete degradation of malic acid, generating a microbiologically stable wine as well as ensuring a positive aroma contribution by the LAB.

Inoculation with a commercial starter culture will reduce the risks associated with spontaneous MLF. These cultures are selected for their ability to survive in the challenging wine environment and to successfully carry out MLF. Co-inoculation is a strategy with the potential to reduce the duration of MLF and risks associated with after AF inoculation, as well as contributing positive aroma properties to the wine without the excessive production of acetic acid.

The physiochemical parameters that the winemaker can control include the temperature, $\mathrm{pH}$ and $\mathrm{SO}_{2}$ additions. Maintaining temperatures of 18 to $22^{\circ} \mathrm{C}$, a $\mathrm{pH}$ of 3.2 to 3.4 and total $\mathrm{SO}_{2}$ concentrations of below $30 \mathrm{mg} / \mathrm{L}$, will optimise conditions for bacterial survival and proliferation. Besides these parameters, a crucial decision by the winemaker involves the selection of the yeast strain to perform AF and the bacteria strain selected for MLF. This selection is an important consideration to ensure minimal antagonistic interactions between the yeast and bacteria that could be detrimental to both the execution of AF and MLF. The yeast strain should produce low amounts of possible inhibitory compounds like $\mathrm{SO}_{2}$ and medium chain fatty acids. The ability of $\mathrm{LAB}$ to survive in the wine environment and withstand the effects of these inhibitory compounds is unequivocally strain dependant.

It has been proven that MLF has a significant impact on the final wine aroma profile. There are various aroma compounds, imparting negative and positive characteristics to the wine, which are produced by the LAB. Factors that influence the production of these compounds need to be investigated. This will provide an invaluable tool in the production of a certain type and style of wine. The production of certain aroma compounds are not just strain dependant, but also differ between the LAB genera. In order to capitalise on these differences, novel approaches for the development of starter cultures are needed. Different genera of LAB as well as a mixture of LAB cultures could be considered for future use in starter cultures.

The continuous monitoring of MLF is essential and often neglected by winemakers. This allows the winemaker to follow the progression of malic acid degradation as well as the bacteria responsible for the fermentation. This is also a way for the winemaker to identify possible difficulties before they can affect the quality of the wine.

Successful MLF is a process that requires specific bacterial strain selection, particular physiochemical parameters and constant monitoring. 


\section{LITERATURE CITED}

Alexandre, H., Costello, P.J., Remize, F., Guzzo, J. \& Guilloux-Benatier, M., 2004. Saccharomyces cerevisiae-Oenococcus oeni interactions in wine: current knowledge and perspectives. Int. J. Food Microbiol. 93, 141-154.

Alexandre, H., Heintz, D., Chassagne, D., Guilloux-Benatier, M., Charpentier, C. $\&$ Feuillat, M., 2001. Protease A activity and nitrogen fractions released during alcoholic fermentation and autolysis in enological conditions. J. Ind. Microbiol. Biotech. 26, 235-240.

Amachi, T., 1975. Chemical structure of a growth factor (TJF) and its physical significance for malo-lactic bacteria. In: Carr, J.G., Cutting, C.V. \& Whiting, G.C. (eds). Lactic Acid Bacteria in Beverages and Foods. Academic Press, London. pp. 103-118.

Araque, I., Gil, J., Carreté, R., Bordons, A. \& Reguant, C., 2009. Detection of arc genes related with the ethyl carbamate precursors in wine lactic acid bacteria. J. Agric. Food Chem. 57, 1841-1847.

Arena, M.E. \& Manca de Nadra, M.C., 2001. Biogenic amine production by Lactobacillus. J. Appl. Microbiol. 90, 158-162.

Arena, M.E. \& Manca de Nadra, M.C., 2002. Comparative survey in Lactobacillus plantarum of the growth and metabolism of arginine and citrulline in different media. J. Agric. Food Chem. 50, 6497-6500.

Arnink, K. \& Henick-Kling, T., 2005. Influence of Saccharomyces cerevisiae and Oenococcus oeni strains on successful malolactic conversion in wine. Am. J. Enol. Vitic. 56, 228-237.

Barbagallo, R.N., Spagna, G., Palmeri, R. \& Torriani, S., 2004. Assessment of $\beta$-glucosidase activity in selected wild strains of Oenococcus oeni for malolactic fermentation. Enzyme Microb. Tech. 34, 292-296.

Bartowsky, E., 2003. Lysozyme and winemaking. Aust. N.Z. Grapegrow. Winemak. 473a, 101-104.

Bartowsky, E.J., 2005. Oenococcus oeni and malolactic fermentation- moving into the molecular arena. Aust. J. Grape Wine Res. 11, 174-187.

Bartowsky, E.J., Costello, P. \& Henschke, P.A., 2002b. Management of malolactic fermentation - wine flavour manipulation. Aust. N.Z. Grapegrow. Winemak. 461, 7-8 and $10-12$.

Bartowsky, E.J., Costello, P.J., Villa, A. \& Henschke, P.A., 2004. The chemical and sensorial effects of lysozyme addition to red and white wines over six months cellar storage. Aust. J. Grape Wine Res. 10, 143-150.

Bartowsky, E., Francis, I.L., Bellon, J.R. \& Henschke, P.A., 2002a. Is buttery aroma perception in wines predictable from the diacetyl concentration? Aust. J. Grape Wine Res. 8, 180-185.

Bartowsky, E.J. \& Henschke, P.A., 1995. Malolactic fermentation and wine flavour. Aust. Grapegrow. Winemak. 378, 83-94.

Bartowsky, E.J. \& Henschke, P.A., 1999. Use of a polymerase chain reaction for specific detection of the malolactic fermentation bacterium O. oeni (formerly Leuconostoc oenos) in grape juice and wine samples. Aust. J. Grape Wine Res. $5,39-44$.

Bartowsky, E.J. \& Henschke, P.A., 2004. The "buttery" attribute of wine - diacetyl - desirability, spoilage and beyond. Int. J. Food Microbiol. 96, 235-252.

Bartowsky, E.J., McCarthy, J.M. \& Henschke, P.A., 2003. Differentiation of Australian wine isolates of Oenococcus oeni using random amplified polymorphic DNA (RAPD). Aust. J. Grape Wine Res. 9, 122-126.

Bauer, R. \& Dicks, L.M.T., 2004. Control of malolactic fermentation in wine. A review. S. Afr. J. Enol. Vitic. 25, 74-88.

Beelman, R.B., Gavin, A. III \& Keen, R.M., 1977. Anew strain of Leuconostocoenos for induced malolactic fermentation in eastern wines. Am. J. Enol. Vitic. 28, 159165 .

Boido, E., Lloret, A., Medina, K., Carrau, F. \& Dellacassa, E., 2002. Effect of $\beta$-glucosidase activity of Oenococcus oeni on the glycosylated flavor precursors of Tannat wine during malolactic fermentation. J. Agric. Food Chem. 50, 23442349 .

Bou, M. \& Krieger S., 2004. Alcohol-tolerant malolactic strains for the maturation of wines with average or high $\mathrm{pH}$. Pub. $\mathrm{N}^{\mathrm{o}}$ : WO/2004/111179.

Bou, M. \& Powell, C., 2006. Strain selection techniques. In: Morenzoni, R. (ed). Malolactic fermentation in wine - understanding the science and the practice. Lallemand, Montréal. pp. 6.1-6.8.
Boulton, R.B., Singleton, V.L., Bisson, L.F. \& Kunkee, R.E., 1996 (1st ed.). Principles and Practices of Winemaking. Chapman and Hall Publishers, New York.

Britz, T.J. \& Tracey, R.P., 1990. The combination effect of $\mathrm{pH}, \mathrm{SO}_{2}$, ethanol and temperature on the growth of Leuconostoc oenos. J. Appl. Bacteriol. 68, 23-31.

Cabrita, M.J., Torres, M., Palma, V., Alves, E., Patão, R. \& Costa Freitas, A.M., 2008. Impact of malolactic fermentation on low molecular weight phenolic compounds. Talanta 74, 1281-1286.

Campos, F.M., Couto, J.A. \& Hogg, T.A., 2003. Influence of phenolic acids on growth and inactivation of Oenococcus oeni and Lactobacillus hilgardii. J. Appl. Microbiol. 94, 167-174.

Campos, F.M., Figueiredo, A.R., Hogg, T.A. \& Couto, J.A., 2009. Effect of phenolic acids on glucose and organic acid metabolism by lactic acid bacteria from wine. Food Microbiol. 26, 409-414.

Capozzi, V., Russo, P., Beneduce, L., Weidmann, S., Grieco, F., Guzzo, J. \& Spano, G., 2010. Technological properties of Oenococcus oeni strains isolated from typical southern Italian wines. Lett. Appl. Microbiol. 50, 327-334.

Capucho, I. \& San Ramao, M.V., 1994. Effect of ethanol and fatty acids on malolactic activity of Leoconostoc oenos. Appl. Microbiol. Biotech. 42, 723-726.

Carreté, R., Vidal, M.T. \& Bordons, A., 2002. Inhibitory effect of sulphur dioxide and other stress compounds in wine on the ATPase activity of Oenococcus oeni. FEMS Microbiol. Lett. 211, 155-159.

Cavin, J.F., Andioc, V., Etievant, P.X. \& Diviès, C., 1993. Ability of wine lactic acid bacteria to metabolize phenol carboxylic acids. Am. J. Enol. Vitic. 44, 7680

Chatonnet, P., Dubourdieu, D., Boidron, J.N. \& Pons, M., 1992. The origin of ethylphenols in wines. J. Sci. Food Agric. 60, 165-178.

Cheynier, V., Dueñas-Paton, M., Salas, E., Maury, C., Souquet, J., Sarni-Manchado, P. \& Fulcrand, H., 2006. Structure and properties of wine pigments and tannins. Am. J. Enol. Vitic. 57, 298-305.

Chu-Ky, S., Tourdot-Marechal, R., Marechal, P.-A. \& Guzzo, J., 2005. Combined cold, acid, ethanol shocks in Oenococcus oeni: Effects on membrane fluidity and cell viability. Biochim. et Biophys. Acta 1717, 118-124.

Comitini, F., Ferretti, R., Clementi, F., Mannazzu, I. \& Ciani, M., 2005. Interactions between Saccharomyces cerevisiae and malolactic bacteria: preliminary characterization of a yeast proteinaceous compound(s) active against Oenococcus oeni. J. Appl. Microbiol. 99, 105-111.

Costello, P., 2006. The chemistry of malolactic fermentation. In: Morenzoni, R. (ed.). Malolactic fermentation in wine - understanding the science and the practice. Lallemand, Montréal. pp. 4.1-4.11.

Costello, P.J. \& Henschke, P.A., 2002. Mousy off-flavour of wine: precursors and biosynthesis of the causative N-heterocycles 2-ethyltetrahydropyradine, 2-acetyltetrahydropyridine, and 2-acetyl-1-pyrroline by Lactobacillus hilgardii DSM 20176. J. Agric. Food Chem. 50, 7079-7087.

Costello, P.J., Henschke, P.A. \& Markides, A.J., 2003. Standardised methodology for testing malolactic bacteria and wine yeast compatability. Aust. J. Grape Wine Res. 9, 127-137.

Costello, P., Lee, T.H. \& Henschke, P.A., 2001. Ability of lactic acid bacteria to produce N-heterocycles causing mousy off-flavour in wine. Aust. J. Grape Wine Res. 7, 160-167.

Couto, J.A., Rozès, N. \& Hogg, T., 1996. Ethanol induced changes in the fatty acid composition of Lactobacillus hilgardii, its effects on plasma membrane fluidity and relationships with ethanol tolerance. J. Appl. Bacteriol. 81, 126-132.

Davis, C.R., Wibowo, D., Eschenbruch, R., Lee, T.H. \& Fleet, G.H., 1985. Practical implications of malolactic fermentation: A review. Am. J. Enol. Vitic. 36, 290-301.

Davis, C.R., Wibowo, D., Fleet, G.H. \& Lee, T.H., 1986b. Growth and metabolism of lactic acid bacteria during fermentation and conservation of some Australian wines. Food Technol. Aust. 38, 35-40.

Davis, CR., Wibowo, D., Fleet, GH. \& Lee, TH., 1988. Properties of wine lactic acid bacteria: Their potential enological significance. Am. J. Enol. Vitic. 39, 137142 .

Davis, C.R., Wibowo, D.J., Lee, T.H. \& Fleet, G.H., 1986a. Growth and metabolism of lactic acid bacteria during and after malolactic fermentations of wines at different pH. Appl. Environ. Microbiol. 51, 539-545. 
De las Rivas, B., Marcobal, Á., Carrascose, A.V. \& Muñoz, R., 2006. PCR detection of foodborne bacteria producing the biogenic amines histamine, tyramine, putrescine, and cadaverine. J. Food Protect. 69, 2509-2514.

Delaquis, P., Cliff, M., King., M., Girard, B., Hall, J. \& Reynolds, A., 2000. Effect of two commercial malolactic cultures on the chemical and sensory properties of Chancellor wines vinified with different yeast and fermentation temperatures. Am. J. Enol. Vitic. 51, 42-48

De Revel, G., Martin, N., Pripis-Nicolau, L., Lonvaud-Funel, A. \& Bertrand, A., 1999. Contribution to the knowledge of malolactic fermentation influence on wine aroma. J. Agric. Food Chem. 47, 4003-4008.

Dicks, L.M.T. \& Endo, A., 2009. Taxonomic status of lactic acid bacteria in wine and key characteristics to differentiate species. S. Afr. J. Enol. Vitic. 30, 72-90.

D’Incecco, N., Bartowsky, E., Kassara, S., Lante, A., Spettoli, P. \& Henschke, P., 2004. Release of glycosidically bound flavour compounds of Chardonnay by Oenococcus oeni during malolactic fermentation. Food Microbiol. 21, 257-265.

Donnelly, D.M., 1997. Airborne microbial contamination in a winery bottling room. Am. J. Enol. Vitic. 28, 176-181.

Drici-Cachon, A., Guzzo, J., Cavin, F. \& Diviès, C., 1996. Acid tolerance in Leuconostoc oenos. Isolation and characterisation of an acid resistant mutant. Appl. Microbiol. Biotech. 44, 785-789.

Du Plessis, L.D.W., 1963. The microbiology of South African winemaking. Part V. Vitamin and amino acid requirements of lactic acid bacteria from dry wines. S. Afr. J. Enol. Sci. 6, 485-494.

Edwards, C.G., Beelman, R.B., Bartley, C.E. \& McConnell, A.L., 1990 Production of decanoic acid and other volatile compounds and the growth of yeast and malolactic bacteria during vinification. Am. J. Enol. Vitic. 41, 48-56.

Fernandes, J.O. \& Ferreira, M.A., 2000. Combined ion-pair extraction and gas chromatography-mass spectrometry for the simultaneous determination of diamines, polyamines and aromatic amines in Port wine and grape juice. J. Chromatogr. A. 886, 183-195.

Fleet, G.H. \& Heard, G.M., 1993. Yeast growth during fermentation. In: Fleet, G.H. (ed.). Wine Microbiology and Biotechnology. Harwood Academic Publishers, Chur, Switzerland. pp. 27-54

Fornachon, J.C.M., 1963. Inhibition of certain lactic acid bacteria by free and bound sulphur dioxide. J. Science Food Agric. 14, 857-862.

Francis, I.L. \& Newton, J.L., 2005. Determining wine aroma from compositional data. Aust. J. Grape Wine Res. 11, 114-126.

Fugelsang, K.C. \& Edwards, C.G., 1997 (2nd ed). Wine Microbiology: Practical Applications and Procedures. Springer, New York.

Fugelsang, K.C. \& Zoecklein, B.W., 1993. MLF Survey. In: Fugelsang, K.C. \& Edwards, C.G. (eds). Wine Microbiology: Practical Applications and Procedures (2nd ed). Springer, New York. pp. 131-132.

G-Alegría, E., López, I., Ruiz, J.I., Sáenz, J., Fernández, E., Zarazaga, M., Dizi, M., Torres, C. \& Ruiz-Larrea, F., 2004. High tolerance of wild Lactobacillus plantarum and Oenococcus oeni strains to lyophilisation and stress environmental conditions of acid $\mathrm{pH}$ and ethanol. FEMS Microbiol. Lett. 230, 53-61.

Gámbaro, A., Boido, E., Zlotejablko, A., Medina, K., Lloret, A., Dellacassa, E. \& Carrau, F., 2001. Effect of malolactic fermentation on the aroma properties of Tannat wine. Aust. J. Grape Wine Res. 7, 27-32.

Gao, Y.-C., Zhang, G., Krentz, S., Darius, S., Power, J. \& Lagarde, G., 2002. Inhibition of spoilage lactic acid bacteria by lysozyme during wine alcoholic fermentation. Austr. J. Grape Wine Res. 8, 76-83.

García-Ruiz, A., Bartolomé, B., Martínez-Rodríguez, A.J., Pueyo, E., MartínÁlvarez, P.J. \& Moreno-Arribas, M.V., 2008. Potential of phenolic compounds for controlling lactic acid bacteria growth in wine. Food Control 19, 835-841.

Gardini, F., Zaccarelli, A., Belletti, N., Faustini, F., Cavazza, A., Maruscelli, M., Mastrocola, D. \& Suzzi, G., 2005. Factors influencing biogenic amine production by a strain of Oenococcus oeni in a model system. Food Control 16, 609-616.

Garvie, E.I., 1967. The growth factor and amino acid requirements of species of the genus Leuconostoc, including Leuconostoc paramesenteroides (sp. nov.) and Leuconostoc oenos. J. Gen. Microbiol. 48, 48, 439-447.

Garvie, E.I. \& Mabbitt, L.A. 1967. Stimulation of growth of Leuconostoc oenos by tomato juice. Arch. Microbiol. 55, 398-407.

Gerbaux, V. \& Monamy, C., 2000. Biogenic amines in Burgundy wines. Contents and origin in wines. Rev. Fr. Oenol. 183, 25-28.
Gerbaux, V., Villa, A., Monamy, C. \& Bertrans, A., 1997. Use of lysozyme to inhibit malolactic fermentation and to stabilize wine after malolactic fermentation. Am. J. Enol. Vitic. 48, 49-54.

Gockowiak H. \& Henschke P.A., 2003. Interaction of pH, ethanol concentration and wine matrix on induction of malolactic fermentation with commercial 'direct inoculation' starter cultures. Aust. J. Grape Wine Res. 9, 200-209.

Green, J.L. \& Daeschel, M.A., 1994. The effects of wine components on the activity of lysozyme in a model wine system. Am. J. Enol. Vitic. 45, 355.

Grimaldi, A., Bartowsky, E. \& Jiranek, V., 2005a. Screening of Lactobacillus spp. and Pediococcus spp. for glycosidase activities that are important in oenology. J. Appl. Microbiol. 99, 1061-1069.

Grimaldi, A., Bartowsky, E. \& Jiranek, V., 2005b. A survey of glycosidase activities of commercial wine strains of Oenococcus oeni. Int. J. Food Microbiol. $105,233-244$

Grimaldi, A., McLean, H. \& Jiranek, V., 2000. Identification and partial characterization of glycosidic activities of commercial strains of the lactic acid bacterium, Oenococcus oeni. Am. J. Enol. Vitic. 51, 362-369.

Guerrini, S., Mangani, S., Granchi, L. \& Vincenzini, M., 2002. Biogenic amine production by Oenococcus oeni. Curr. Microbiol. 44, 374-378.

Guerzoni, M.E., Sinigaglia, M., Gardini, F., Ferruzzi, M. \& Torriani, S., 1995. Effects of $\mathrm{pH}$, temperature, ethanol and malate concentration on Lactobacillus plantarum and Leuconostoc oenos: Modeling of the malolactic activity. Am. J. Enol. Vitic. $46,368-374$.

Guilloux-Benatier, M. \& Chassagne, D., 2003. Comparison of components released by fermented or active dried yeasts after aging on lees in a model wine. J. Agric. Food Chem. 51, 746-751.

Guilloux-Benatier, M., Remize, F., Gal, L., Guzzo, J. \& Alexandre, H., 2006. Effects of yeast proteolytic activity on Oenococcus oeni and malolactic fermentation. FEMS Microbiol. Lett. 263, 183-188.

Guzzo, J., Jobin, M.-P. \& Diviès, C., 1998. Increase of sulfite tolerance in Oenococcus oeni by means of acidic adaptation. FEMS Microbiol. Lett. 160, 4347.

Guzzon, R., Poznanski, E., Conterno, L., Vagnoli, P., Krieger-Weber, S. \& Cavazza, A., 2009. Selection of a new highly resistant strain for malolactic fermentation under difficult conditions. S. Afr. J. Enol. Vitic. 30(2), 133-141.

Henick-Kling, T., 1993. Malolactic fermentation. In: Fleet, G.H. (ed.). Wine Microbiology and Biotechnology, Harwood Academic Publishers, Chur, Switzerland, pp. 289-326.

Henick-Kling, T., 1995. Control of malolactic fermentation in wine: energetics, flavour modification and methods of starter culture preparation. J. Appl. Bacteriol. Symp. Supp. 79, 296S-37S.

Henick-Kling, T. \& Park, Y.H., 1994. Considerations for the use of yeast and bacterial starter cultures: $\mathrm{SO}_{2}$ and timing of inoculation. Am. J. Enol. Vitic. 45, 464-469.

Herjavec, S., Tupajić, P. \& Majdak, A., 2001. Influence of malolactic fermentation on the quality of Riesling wine. Agric. Conspec. Sci. 66, 59-64.

Hernández, T., Estrella, I., Carlavilla, D., Martín-Álvarez, P.J. \& Moreno-Arribas, M.V., 2006. Phenolic compounds in red wine subjected to industrial malolactic fermentation and ageing on lees. Analytica Chimica Acta, 563, 116-125.

Hernández, T., Estrella, I., Pérez-Gordo, M., Alegría, E.G., Tenorio, C., Ruiz-Larrea, F. \& Moreno-Arribas, M.V., 2007. Contribution of malolactic fermentation by Oenococcus oeni and Lactobacillus plantarum to the changes in the nonanthocyanin polyphenolic composition of red wine. J. Agric. Food. Chem. $55,5260-5266$.

Hernandez-Orte, P., Cersosimo, M., Loscos, N., Cacho, J., Garcia-Moruno, E. \& Ferreira, V., 2009. Aroma development from non-floral grape precursors by wine lactic acid bacteria. Food Res. Int. 42, 773-781.

Izquierdo Cañas, P.M., García Romero, E., Gómez Alonso, S., Fernández González, M. \& Palop Herreros, M.L.L., 2007. Amino acids and biogenic amines during spontaneous malolactic fermentation in Tempranillo red wines. J. Food Compos. Anal. 21, 731-735.

Izquierdo Cañas, P.M., Gómez Alonso, S., Ruiz Pérez, P., Seseña Prieto, S., García Romero, E. \& Palop Herreros, M.L.L., 2009. Biogenic amine production by Oenococcus oeni isolates from malolactic fermentation of Tempranillo wine. J. Food Protec. 72, 907-910. 
Jackson, R.S., 2008 (3rd ed). Wine Science: Principles and applications. Academic Press, California, USA. p. 394.

Jeromel, A., Herjavec, S., Orlić, S., Redžepović, S. \& Wondra, M., 2008. Changes in volatile composition of Kraljevina wines by controlled malolactic fermentation. J. Cent. Eur. Agric. 9, 363-372

Jussier, D., Morneau, A.D. \& Mira de Orduña, R.M., 2006. Effect of simultaneous inoculation with yeast and bacteria on fermentation kinetics and key wine parameters of cool-climate Chardonnay. Appl. Environ. Microbiol. 72, 221-227.

King, S.W. \& Beelman, R.B., 1986. Metabolic interactions between Saccharomyces cerevisiae and Leuconostoc oenos in a model grape juice/wine system. Am. J. Enol. Vitic. 37, 53-60.

Koebmann, B.J., Nilsson, D., Kuipers, O.P. \& Jensen, P.R., 2000. The membranebound $\mathrm{H}^{+}$-ATPase complex is essential for growth of Lactococcus lactis. J. Bacteriol. 182, 4738-4743.

Kollar, S. \& Brown, N., 2006. Monitoring malolactic fermentation. In: Morenzoni, R. (ed). Malolactic fermentation in wine - understanding the science and the practice. Lallemand, Montréal. pp. 14.1-14.8.

Konings, W.N., 2002. The cell membrane and the struggle for life of lactic acid bacteria. Antonie Van Leeuwenhoek 82, 3-27.

Krieger, S., 2006. Determining when to add malolactic bacteria. In: Morenzoni, R. (ed). Malolactic fermentation in wine - understanding the science and the practice. Lallemand, Montréal. pp. 12.1-12.10.

Krieger-Weber, S., 2009. Application of yeast and bacteria as starter cultures. In: König, H., Unden, G. \& Fröhlich, J. (eds). Biology of microorganisms on grapes, in must and in wine. Springer, Berlin. pp. 498-511.

Kunkee, R.E., 1967. Control of malolactic fermentation induced by Leuconostoc citrovorum. Am. J. Enol. Vitic. 18, 71-77.

Kunkee, RE., 1991. Some roles of malic acid in the malolactic fermentation in wine making. FEMS Microbiol. Lett. 88, 55-72.

Lafon-Lafourcade, S., Carre, E. \& Ribéreau-Gayon, P., 1983. Occurrence of lactic acid bacteria during different stages of the vinification and conservation of wines. Appl. Environ. Microbiol. 46, 874-880.

Landaud, S., Helinck, S. \& Bonnarme, P., 2008. Formation of volatile sulphur compounds and metabolism of methionine and other sulphur compounds in fermented food. Appl. Microbiol. Biotechnol. 77, 1191-1205.

Landete, J.M., Ferrer, S. \& Pardo, I., 2005a. Which lactic acid bacteria are responsible for histamine production in wine? J. Appl. Microbiol. 99, 580-586.

Landete, J.M., Ferrer, S. \& Pardo, I., 2007a. Biogenic amine production by lactic acid bacteria, acetic bacteria and yeast isolated from wine. Food Control 18, 15691574

Landete, J.M., Ferrer, S., Polo, L. \& Pardo, I., 2005b. Biogenic amines in wines from three Spanish regions. J. Agr. Food Chem. 53, 1119-1124.

Landete, J.M., Pardo, I. \& Ferrer, S., 2007b. Tyramine and phenylethylamine production among lactic acid bacteria isolated from wine. Int. J. Food Microbiol. $115,364-368$

Landete, J.M., Pardo, I. \& Ferrer, S., 2008. Regulation of $h d c$ expression and HDC activity by enological factors in lactic acid bacteria. J. Appl. Microbiol. 105, 15441551

Larsen, J.T., Nielsen, J.-C., Kramp, B., Richelieu, M., Bjerring, P., Riisager, N.A. \& Edwards, C.G., 2003. Impact of different strains of Saccharomyces cerevisiae on malolactic fermentation by Oenococcus oeni. Am. J. Enol. Vitic. 54, 246-251.

Le Jeune, C., Lonvaud-Funel, A., Ten Brink, B., Hofstra, H. \& Van der Vossen, J.M.B.M., 1995. Development of a detection system for histidine decarboxylating lactic acid bacteria based on DNA probes, PCR and activity test. J. Appl. Bacteriol. 78, 316-326.

Liu, S-Q., 2002. A review: Malolactic fermentation in wine - beyond deacidification. J. Appl. Microbiol. 92, 589-601.

Liu, M., Nauta, A., Francke, C. \& Siezen, R.J., 2008. Comparative genomics of enzymes in flavour-forming pathways from amino acids in lactic acid bacteria. Appl. Environ. Microbiol. 74, 4590-4600.

Liu, S.-Q.,Prichard, G.C.,Hardman, M.J.\&Pilone, G.C., 1994.Citrulline production and ethyl carbamate (urethane) precursor formation from arginine degradation by wine lactic acid bacteria Leuconostoc oenos and Lactobacillus buchneri. Am. J. Enol. Vitic. 45, 235-242.
Liu, S.-Q., Pritchard, G.G., Hardman, M.J. \& Pilone, G.J., 1995. Occurrence of arginine deiminase pathway enzymes in arginine catabolism by lactic acid bacteria. Appl. Environ. Microbiol. 61, 610-316.

Lloret, A., Boido, E., Lorenzo, D., Medina, K., Carrau, F. \& Dellacassa, E., 2002. Aroma variation in Tannat wines: Effect of malolactic fermentation on ethyl lactate level and its enantiomeric distribution. Ital. J. Food. Sci. 14, 175-180.

Lonvaud-Funel, A., 1995. Microbiology of the malolactic fermentation: Molecular aspects. FEMS Microbiol. Lett. 126, 209-214.

Lonvaud-Funel, A., 1999. Lactic acid bacteria in the quality improvement and depreciation of wine. Antonie van Leeuwenhoek 76, 317-331.

Lonvaud-Funel, A., 2001. Biogenic amines in wine: role of lactic acid bacteria. FEMS Microbiol. Lett. 199, 9-13.

Lonvaud-Funel, A. \& Joyeux, A., 1994. Histamine production by wine lactic acid bacteria: isolation of a histamine-producing strain of Leuconostoc oenos. J. Appl. Bacteriol. 77, 401-407.

Lonvaud-Funel, A., Joyeux, A. \& Desens, C., 1988. The inhibition of malolactic fermentation of wines by products of yeast metabolism. J. Food. Sci. Technol. 44, 183-191.

Lonvaud-Funel, A., Joyeux, A. \& Ledoux, O., 1991. Specific enumeration of lactic acid bacteria in fermenting grape must and wine by colony hybridisation with nonisotopic DNA probes. J. Appl. Bacteriol. 71, 501-508.

Lucas, P.M., Claisse, O. \& Lonvaud-Funel, A., 2008. High frequency of histamineproducing bacteria in enological environment and instability of the phenotype. Appl. and Environ. Microbiol. 74, 811-817.

Maicas, S., Gil, J-V., Pardo, I. \& Ferrer, S., 1999. Improvement of volatile composition of wines by controlled addition of malolactic bacteria. Food Res. Int. 32, 491 .

Mañes-Lázaro, R., Ferrer, S., Rodas, A. M., Urdiain, M., \& Pardo, I., 2008a. Lactobacillus bobalius sp. nov., a lactic acid bacterium isolated from Spanish Bobal grape must. Int. J. System. Evol. Microbiol. 58, 2699-2703.

Mañes-Lázaro, R., Ferrer, S., Rosselló-Mora, R., \& Pardo, I., 2008b. Lactobacillus uvarum sp. nov.-A new lactic acid bacterium isolated from Spanish Bobal grape must. System. Appl. Microbiol. 31, 425-433.

Mañes-Lázaro, R., Ferrer, S., Rosselló-Mora, R., \& Pardo, I., 2009. Lactobacillus oeni sp. nov., from wine. Int. J. System. Evol. Microbiol. 59, $2010-$ 2014.

Manfroi, L., Silva, P.H.A., Rizzon, L.A., Sabaini, P.S. \& Glória, M.B.A., 2009. Influence of alcoholic and malolactic starter cultures on bioactive amines in Merlot wines. Food Chem. 116, 208-213.

Mansfield, A.K., Zoecklein, B.W. \& Whiton, R.S., 2002. Quantification of glycosidase activity in selected strains of Brettanomyces bruxellensis and Oenococcus oeni. Am. J. Enol. Vitic. 53, 303-307.

Marcobal, Á., De Las Rivas, B., Moreno-Arribas, M.V. \& Muñoz, R., 2004. Identification of the ornithine decarboxylase gene in the putrescine-producer Oenococcus oeni BIFI-83. FEMS Microbiol. Lett. 239, 213-220.

Marcobal, Á., De Las Rivas, B., Moreno-Arribas, M.V. \& Muñoz, R, 2005. Multiplex PCR method for the simultaneous detection of histamine-, tyramine-, and putrescine producing lactic acid bacteria in foods. J. Food Protect. 68, 874878 .

Marcobal, Á., Martín-Álvarez, P.J., Polo, C., Muñoz, R. \& Moreno-Arribas, M.V., 2006. Formation of biogenic amines throughout the industrial manufacture of red wine. J. Food Protect. 69, 397-404.

Martín-Álvarez, P.J., Marcobal, Á., Polo, C. \& Moreno-Arribas, M.V., 2006. Influence of technological practices on biogenic amine contents in red wines. Eur. Food Res. Technol. 222, 420-424.

Martineau, B., Acree, T.E. \& Henick-Kling, T., 1995. Effect of wine type on the detection threshold for diacetyl. Food Res. Int. 28, 139-143.

Matthews, A.H., Grbin, P.R. \& Jiranek, V., 2006. A survey of lactic acid bacteria for enzymes of interest to oenology. Aust. J. Grape Wine Res. 12, 235-244.

Matthews, A., Grbin, P.R. \& Jiranek, V., 2007. Biochemical characterisation of the esterase activities of wine lactic acid bacteria. Appl. Microbiol. Biotechnol. 77, 329-337.

Matthews, A., Grimaldi, A., Walker, M., Bartowsky, E., Grbin, P. \& Jiranek, V., 2004. Lactic acid bacteria as a potential source of enzymes for use in vinification. Appl. Environ. Microbiol. 70, 5715-5731. 
Mazzoli, R., Lamberti, C., Coisson, J.D., Purrotti, M., Arlorio, M., Guiffrida, M.G., Guinta, C. \& Pessione, E., 2009. Influence of ethanol, malate and arginine on histamine production of Lactobacillus hilgardii isolated from Italian red wine. Amino Acids 36, 81-89.

McKenzie, H.A. \& White, F.H., 1991. Lysozyme and alpha-lact-albumin: Structure, function and interrelationships. Adv. Prot. Chem. 41, 173-315.

McMahon, H., Zoecklein, B.W., Fugelsang, K. \& Jasinsky, Y., 1999. Quantification of glycosidase activities in selected yeasts and lactic acid bacteria. J. Ind. Microbiol. Biotechnol. 23, 198-203

Mira de Orduña, R., Liu, S.-Q., Patchett, M.L. \& Pilone, G.J., 2000. Ethyl carbamate precursor citrulline formation from arginine degradation by malolactic wine lactic acid bacteria. FEMS Microbiol. Lett. 183, 31-35.

Mira de Orduña, R., Patchett, M.L., Liu, S.-Q. \& Pilone, G.J., 2001. Growth and arginine metabolism of the wine lactic acid bacteria Lactobacillus buchneri and Oenococcus oeni at different $\mathrm{pH}$ values and arginine concentrations. Appl. Environ. Microbiol. 67, 1657-1662.

Moreno-Arribas, V. \& Lonvaud-Funel, A., 1999. Tyrosine decarboxylase activity of Lactobacillus brevis IOEB 9809 isolated from wine and L. brevis ATCC 367. FEMS Microbiol. Lett. 180, 55-60.

Moreno-Arribas, M.V. \& Polo, M.C., 2008. Occurrence of lactic acid bacteria and biogenic amines in biologically aged wines. Food Microbiol. 25, 875-881.

Moreno-Arribas, V., Polo, M.C., Jorganes, F. \& Muñoz, R., 2003. Screening of biogenic amine production by lactic acid bacteria isolated from grape must and wine. Int. J. Food Microbiol. 84, 117-123.

Moreno-Arribas, V., Torlois, S., Joyex, A., Bertrand, A. \& Lonvaud-Funel, A., 2000. Isolation, properties and behaviour of tyramine-producing lactic acid bacteria from wine. J. Appl. Microbiol. 88, 584-593.

Mtshali, P.S., Divol, B.T., Van Rensburg, P. \& Du Toit, M., 2010. Genetic screening of wine-related enzymes in Lactobacillus species isolated from South African wine. J. Appl. Microbiol. 108, 1389-1397.

Nault, I., Gerbaux, V., Larpent, J.P. \& Vayssier, Y., 1995. Influence of pre-culture conditions on the ability of Leuconostoc oenos to conduct malolactic fermentation in wine. Am. J. Enol. Vitic. 46, 357-362.

Neeley, E.T., Phister, T.G. \& Mills, D.A., 2005. Differential real-time PCR assay for enumeration of lactic acid bacteria in wine. Appl. Environ. Microbiol. 71, 8954-8957.

Nehme, N., Mathieu, F. \& Taillandier, P., 2008. Quantitative study of interactions between Saccharomyces cerevisiae and Oenococcus oeni strains. J. Ind. Microbiol. Biotechnol. 35, 685-693.

Nehme, N., Mathieu, F. \& Taillandier, P., 2010. Impact of the co-culture of Saccharomyces cerevisiae-Oenococcus oeni on malolactic fermentation and partial characterization of a yeast-derived inhibitory peptidic fraction. Food Microbiol. 27, 150-157.

Nelson, L., 2008. The production of volatile phenols by wine microorganisms. Thesis, Stellenbosch University, Private Bag X1, 7602 Matieland (Stellenbosch), South Africa.

Nielsen, J.C., Prahl, C. \& Lonvaud-Funel, A., 1996. Malolactic fermentation in wine by direct inoculation with freeze-dried Leuconostoc oenos cultures. Am. J. Enol. Vitic. 47, 42-48.

Nielsen, J.C. \& Richelieu, M., 1999. Control of flavour development in wine during and after malolactic fermentation by Oenococcus oeni. Appl. Environ. Microbiol. 65, 740-745.

Nygaard, M. \& Prahl, C., 1997. Compatibility between strains of Saccharomyces cerevisiae and Leuconostoc oenos as an important factor for successful malolactic fermentation. Am. J. Enol. Vitic. 48, 270.

Osborne, J.P. \& Edwards, C.G., 2006. Inhibition of malolactic fermentation by Saccharomyces during alcoholic fermentation under low- and high nitrogen conditions: A study in synthetic media. Aust. J. Grape Wine Res. 12, 69-78.

Osborne, J.P., Dubé Morneau, A. \& Mira de Orduña, R., 2006. Degradation of free and sulphur-dioxide-bound acetaldehyde by malolactic acid bacteria in white wine. J. Appl. Microbiol. 101, 474-479.

Palacios, A., 2006. Organoleptic defects caused by uncontrolled malolactic fermentation. In: Morenzoni, R. (ed). Malolactic fermentation in wine understanding the science and the practice. Lallemand, Montréal. pp. 7.1-7.7.
Peinado, R.A., Moreno, J., Bueno, J.E., Moreno, J.A. \& Mauricio, J.C., 2004. Comparitive study of aromatic compounds in two young white wines subjected to pre-fermentative cryomaceration. Food Chem. 84, 589-590.

Pinzani, P., Bonciani, L., Pazzagli, M., Orlando, C., Geurrini, S. \& Granchi, L., 2004. Rapid detection of Oenococcus oeni in wine by real-time quantitative PCR. Lett. Appl. Microbiol. 38, 118-124.

Powell, C., Van Zandycke, S. \& Degré, R., 2006. The microbiology of malolactic fermentation. In: Morenzoni, R. (ed). Malolactic fermentation in wine understanding the science and the practice. Lallemand, Montréal. pp. 5.1-5.11.

Pozo-Bayón, M.A., G-Alegría, E., Polo, M.C., Tenorio, C., Martín-Álvarez, P.J., Calvo de la Banda, M.T., Ruiz-Larrea, F. \& Moreno Arribas, M.V., 2005. Wine volatile and amino acid composition after malolactic fermentation: Effect of Oenococcus oeni and Lactobacillus plantarum starter cultures. J. Agric. Food Chem. 53, 8729-8735.

Pozo-Bayón, M.A., G-Alegría, E., Polo, M.C., Tenorio, C., Martín-Álvarez, P.J., Calvo de la Banda, M.T., Semon, M.J., Edwards, C.G., Forsyth, D. \& Dinn, C.O., 2001. Inducing malolactic fermentation in Chardonnay musts and wines using different strains of Oenococcus oeni. Aust. J. Grape Wine Res. 7, 52-59.

Pripis-Nicolau, L., De Revel, G., Bertrand, A. \& Lonvaud-Funel, A., 2004. Methionine catabolism and production of volatile sulphur compounds by Oenococcus oeni. J. Appl. Microbiol. 96, 1176-1184.

Pripis-Nicolau, L., De Revel, G., Bertrand, A. \& Maujean, A., 2000. Formation of flavor components by the reaction of amino acid and carbonyl compounds in mild conditions. J. Agric. Food. Chem. 48, 3761-3766.

Rankine, B.C., Fornachon, J.C.M., Bridson \& D.A., Cellier, K.M., 1970. Malolactic fermentation in Australian dry red wines. J. Sci. Food Agric. 21, 471-476.

Reguant, C., Bordons, A., Arola, L. \& Rozès, N., 2000. Influence of phenolic compounds on the physiology of Oenococcus oeni from wine. J. Appl. Microbiol. $88,1065-1071$.

Renouf, V., Claisse, O. \& Lonvaud-Funel, A., 2006. rpoB gene : A target for identification of LAB cocci by PCR-DGGE and melting curves analysis in real time PCR. J. Microbiol. Meth. 67, 162-170.

Ribéreau-Gayon, P., 1985. New developments in wine microbiology. Am. J. Enol. Vitic. 36, 1-10.

Ribéreau-Gayon, P., Glories, Y., Maujean, A. \& Dubourdieu, D., 2002. The chemistry of wine stabilisation and treatments. In: Ribéreau-Gayon P. (ed.). Handbook of Enology, vol 2. Wiley, Chichester, England.

Ribérau-Gayon, P., Dubourdieu, D., Donèche, B. \& Lonvaud, A., 2006 (2nd ed). The microbiology of wine and vinifications. In: Ribéreau-Gayon P. (ed.). Handbook of Enology, vol 1. Wiley, Chichester, England.

Rodas, A.M., Ferrer, S. \& Pardo, I., 2003. 16S-ARDRA, a tool for identification of lactic acid bacteria isolated from grape must and wine. System. Appl. Microbiol. 24, 412-422.

Rollan, G.C., Coton, E. \& Lonvaud-Funel, A., 1995. Histidine decarboxylase activity of Leuconostoc oenos 9204. Food Microbiol. 12, 455-461.

Romano, P. \& Suzzi, G., 1993. Sulphur dioxide and wine microorganisms. In: Fleet, G.H. (ed.). Wine Microbiology and Biotechnology. Harwood Academic Publishers, Chur, Switzerland, pp. 373-393.

Romero, S.V., Reguant, C., Bordons, A. \& Masqué, M.C., 2009. Potential formation of ethyl carbamate in simulated wine inoculated with Oenococcus oeni and Lactobacillus plantarum. Int. J. Food Sc. Technol. 44, 1206-1213.

Rosi, I., Fia, G. \& Canuti, V., 2003. Influence of different pH values and inoculation time on the growth and malolactic activity of a strain of Oenococcus oeni. Aust. J. Grape Wine Res. 9, 194-199.

Rosi, I., Nannelli, F. \& Giovani, G., 2009. Biogenic amine production by Oenococcus oeni during malolactic fermentation of wines obtained using different strains of Saccharomyces cerevisiae. Food Sc. Technol. 42, 525-530.

Rozès, N., Arola, L. \& Bordons, A., 2003. Effect of phenolic compounds on the co-metabolism of citric acid and sugars by Oenococcus oeni from wine. Lett. Appl. Microbiol. 36, 337-341.

Rozès, N. \& Perez, C., 1998. Effects of phenolic compounds on the growth and the fatty acid composition of Lactobacillus plantarum. Appl. Microbiol. Biotech. 49, 108-111.

Ruiz, P., Izquierdo, P.M., Seseña, S. \& Palop, M.L., 2010. Selection of autochthonous Oenococcus oeni strains according to their oenological properties and vinification results. Int. J. Food. Microbiol. 137, 230-235. 
Saguir, F.M., Campos, I.E.L., Maturano, C. \& Manca de Nadra, M.C., 2009. Identification of dominant lactic acid bacteria isolated from grape juices. Assessment of its biochemical activities relevant to flavor development in wine. Int. J. Wine Res. 1, 175-185.

Sauvageot, F. \& Vivier, P., 1997. Effects of malolactic fermentation on sensory properties of four Burgundy wines. Am. J. Enol. Vitic. 48, 187-192.

Sefton, M.A., Francis, I.L. \& Williams, P.J., 1993. The volatile composition of Chardonnay juices: a study by flavor precursor analysis. Am. J. Enol. Vitic. 44, 359-370.

Shalaby, A.R., 1996. Significance of biogenic amines to food safety and human health. Food Res. Int. 29, 675-690.

Smit, A.Y., Du Toit, W.J. \& Du Toit, M., 2008. Biogenic amines in wine Understanding the headache. S. Afr. J. Enol. Vitic. 29, 109-127.

Spano, G., Lonvaud-Funel, A., Claisse, O. \& Massa, S., 2007. In vivo PCR-DGGE analysis of Lactobacillus plantarum and Oenococcus oeni populations in red wine. Curr. Microbiol. 54, 9-13.

Spano, G., Rinaldi, A., Ugliano, L., Moio, L., Beneduce, L. \& Massa, S., 2005. A $\beta$-glucosidase gene isolated from wine Lactobacillus plantarum is regulated by abiotic stresses. J. Appl. Microbiol. 98, 855-861.

Specht, G., 2006. Guidelines for using commercial strains. In: Morenzoni, R. (ed). Malolactic fermentation in wine - understanding the science and the practice. Lallemand, Montréal. pp. 11.1-11.3.

Stead, D., 1993. The effect of hydroxycinnamic acids on the growth of winespoilage lactic acid bacteria. J. Appl. Bacteriol. 75, 135-141.

Sumby, K.M., Grbin, P.R. \& Jiranek, V., 2009. Microbial modulation of aromatic esters in wine: Current knowledge and prospects. Food Chem. 121, 1-16.

Suzzi., G., Romano, P. \& Zambonelli, C., 1985. Saccharomyces strain selection in minimizing $\mathrm{SO}_{2}$ requirement during vinification. Am. J. Enol. Vitic. 36, 199-202.

Swiegers, J.H., Bartowsky, E.J., Henschke, P.A. \& Pretorius, I.S., 2005. Yeast and bacterial modulation of wine aroma and flavour. Aust. J. Grape Wine Res. 11, 139-173.

Ten Brink., B., Damink, C., Joosten, H.M.L.J. \& Huis in 't Veld, J.H.J., 1990. Occurrence and formation of biologically active amines in foods. Int. J. Food Microbiol. 11, 73-84.

Terrade, N. \& Mira de Orduña, R., 2006. Impact of winemaking practices on arginine and citrulline metabolism during and after malolactic fermentation. J. Appl. Microbiol. 101, 406-411.

Terrade, N. \& Mira de Orduña, R., 2009. Determination of the essential nutrient requirements of wine-related bacteria from the genera Oenococcus and Lactobacillus. Int. J. Food Microbiol. 133, 8-13.

Terrade, N., Noël, R., Couillaud, R. \& Mira de Orduña, R., 2009. A new chemically defined medium for wine lactic acid bacteria. Food. Res. Int. 42, 363-367.

Théodore, D., 2006. Overview - understanding the practice of malolactic fermentation. In: Morenzoni, R. (ed). Malolactic fermentation in wine understanding the science and the practice. Lallemand, Montréal. pp. 10.1-10.3.

Théodore, D., Krieger, S., Costello, P. \& Dumont, A., 2005. Bacterial nutritionthe key to successful malolactic fermentation. Aust. N.Z. Grapegrow. Winemak. April, 65-68.

Tracey, R.P. \& Britz, T.J., 1987. A numerical taxonomic study of Leuconostoc oenos strains from wine. J. Appl. Bacteriol. 63, 525-532.
Ugliano, M., Genovese, A. \& Moio, L., 2003. Hydrolysis of wine aroma precursors during malolactic fermentation with four commercial starter cultures of Oenococcus oeni. J. Agric. Food Chem. 51, 5073-5078.

Ugliano, M. \& Henschke, P.A., 2008. Yeast and wine flavour. In: Moreno-Arribas, M.V. and Polo, C. (eds). Wine chemistry and biochemistry. Springer, New York. pp. 328-348.

Ugliano, M. \& Moio, L., 2005. Changes in the concentration of yeast-derived volatile compounds of red wine during malolactic fermentation with four commercial starter cultures of Oenococcus oeni. J. Agric. Food Chem. 53, 1013410139 .

Ugliano, M. \& Moio, L., 2006. The influence of malolactic fermentation and Oenococcus oeni strain on glycosidic aroma precursors and related volatile compounds of red wine. J. Sci. Food Agric. 86, 2468-2476.

Usseglio-Tomasset, L., 1992. Properties and use of sulphur dioxide. Food Add. Contam. 9, 399-404.

Uthurry, C.A., Suárez Lepe, J.A., Lombardero, J. \& Garcia Del Hierro, J.R., 2006. Ethyl carbamate production by selected yeasts and lactic acid bacteria in red wine. Food Chem. 94, 262-270.

Vaillant, H., Formisyn, P. \& Gerbaux, V., 1995. Malolactic fermentation of wine: study of the influence of some physiochemical factors by experimental design assays. J. Appl. Bacteriol. 79, 640-650.

Vallet, A., Lucas, P., Lonvaud-Funel, A. \& De Revel, G., 2008. Pathways that produce volatile sulphur compounds from methionine in Oenococcus oeni. J. Appl. Microbiol. 104, 1833-1840.

Van der Merwe, H., 2007. The evaluation of malolactic fermentation starter cultures under South African winemaking conditions. Thesis, Stellenbosch University, Private Bag X1, 7602 Matieland (Stellenbosch), South Africa.

Van Vuuren, H.J.J. \& Dicks, L.M.T., 1993. Leuconostoc oenos: A review. Am. J. Enol. Vitic. 44, 99-112.

Vaquero, I., Marcobal, A. \& Muñoz, R., 2004. Tannase activity by lactic acid bacteria isolated from grape and must. Int. J. Food Microbiol. 96, 199-204.

Versari, A., Parpinello, G.P. \& Cattaneo, M., 1999. Leuconostoc oenos and malolactic fermentation in wine: A review. J. Ind. Microbiol. Biotechnol. 23, 447455 .

Vilanova, M. \& Martínez, C., 2007. First study of determination of aromatic compounds of red wine from Vitis vinifera cv. Castanãl grown in Galica (NW Spain). Eur. Food Res. Technol. 224, 431-436.

Vivas, N., Lonvaud-Funel, A. \& Glories, Y., 1997. Effect of phenolic acids and anthocyanins on growth, viability and malolactic activity of a lactic acid bacterium. Food Microbiol. 14, 291-300.

Volschenk, H., van Vuuren, H.J.J. \& Viljoen-Bloom, M., 2006. Malic acid in wine: Origin, function and metabolism during vinification. S. Afr. J. Enol. Vitic. 27, 123-136.

Wibowo, D., Eschenbruch, R., Davis, CR., Fleet, GH. \& Lee, TH., 1985. Occurrence and growth of lactic acid bacteria in wine: A review. Am. J. Enol. Vitic. 36, 302-313.

Zapporoli, G., Torriani, S. \& Dellaglio, F., 1998. Design and evaluation of malolactic enzyme gene targeted primers for rapid identification and detection of Oenococcus oeni in wine. Lett. Appl. Microbiol. 27, 243-246.

Zapparoli, G., Tosi, E., Azzolini, M., Vagnoli, P. \& Krieger, S., 2009. Bacterial inoculation strategies for the achievement of malolactic fermentation in highalcohol wines. S. Afr. J. Enol. Vitic. 30, 49-55. 